\title{
Molecular profile of atypical hyperplasia of the breast
}

\author{
David N. Danforth ${ }^{1}$
}

Received: 20 July 2017/Accepted: 28 August 2017/Published online: 14 September 2017

(c) The Author(s) 2017. This article is an open access publication

\begin{abstract}
Purpose Atypical ductal and atypical lobular hyperplasia (AH) of the breast are important proliferative lesions which are associated with a significantly increased risk for breast cancer. The breast cancer which develops in association with AH may occur synchronously, representing local progression, or metachronously at a later date in either the ipsilateral or contralateral breast. These high-risk characteristics of $\mathrm{AH}$ suggest they contain significant genomic changes.

Methods To define the genomic changes in $\mathrm{AH}$, a comprehensive review of the literature was conducted to identify the numerical chromosomal and structural chromosomal changes, DNA methylation, and gene expression abnormalities in atypical ductal and atypical lobular hyperplasia.

Results AHs are characterized by advanced genomic changes including aneuploidy, loss of heterozygosity, gross chromosomal rearrangements such as amplifications and large-scale deletions, DNA methylation of tumor suppressor and other genes, and gene expression differences between $\mathrm{AH}$ and surrounding normal breast tissue including significant estrogen receptor expression. Many of these changes are shared by an associated synchronous breast cancer, consistent with an important precursor role for $\mathrm{AH}$. At the same time, many of the genomic changes of AHs are also shared by common sporadic breast cancer, consistent
\end{abstract}

David N. Danforth

david_danforth@nih.gov

$1 \quad$ Surgery Branch, Center for Cancer Research, National Cancer Institute, National Institutes of Health, Bethesda, MD 20892, USA with a high risk for future development of metachronous breast cancer.

Conclusions This molecular profile should help clarify the genomic characteristics and malignant predisposition of $\mathrm{AH}$, and aid in the identification of new targets for the prevention of breast cancer

Keywords Atypical hyperplasia - Atypical ductal .

Atypical lobular · Breast high risk - Breast cancer · Breast carcinogenesis $\cdot$ Premalignant breast
Abbreviations
ALH Atypical lobular hyperplasia
ADH Atypical ductal hyperplasia
AH Atypical hyperplasia
AI Allelic imbalance
$\mathrm{CGH}$ Comparative genomic hybridization
DIALH Ductal involvement by cells of atypical lobular hyperplasia
DCIS Ductal carcinoma in situ
ER Estrogen receptor
FISH Fluorescent in situ hybridization
IDC Invasive ductal carcinoma
IHC Immunohistochemistry
LCIS Lobular carcinoma in situ
LOH Loss of heterozygosity
MSI Microsatellite instability
MSP Methylation-specific PCR
NABT Normal adjacent breast tissue
NSABP National Surgical Adjuvant Breast and Bowel Project
PDWA Poorly differentiated without atypia
UDH Usual ductal hyperplasia 


\section{Background}

Atypical lobular (ALH) and atypical ductal (ADH) hyperplasia are proliferative lesions of the breast which are associated with a significantly increased risk for breast cancer. The histologic characteristics of these lesions are well defined $[1,2]$, and ADH and ALH each contain early changes of, respectively, DCIS and LCIS, increasing the likelihood that they will contain at least the early genomic changes of malignancy. Estrogen is a major carcinogen for breast cancer, with the ability to cause single base substitutions, single and double DNA strand breaks, and chromosomal rearrangements [3]. ADH and ALH [collectively atypical hyperplasia $(\mathrm{AH})]$ occur more commonly in women over the age of $55[4,5]$. This allows for a significant (40 plus year) exposure to estrogens and the potential for widespread genomic damage. Individual reports have described the presence of aneuploidy [6], chromosomal gains and losses [7], DNA methylation [8], and gene expression changes [9] in AH lesions, consistent with this exposure. A comprehensive understanding of these genomic changes is needed to further define the nature and spectrum of these genomic alterations and the relationship of these changes to breast cancer.

Atypical ductal and atypical lobular hyperplasia may be associated with the development of synchronous or metachronous breast cancer. Synchronous breast cancer occurs concomitantly with AH and is considered to represent local progression of $\mathrm{AH}$. The incidence of synchronous carcinoma with $\mathrm{AH}$ is, on average, $22.0 \%$ (Table 1). For this reason, $\mathrm{AH}$ lesions are frequently excised at the time of presentation to include these tumors, which provides an important opportunity to define the genomic characteristics of $\mathrm{AH}$ and its associated breast cancer. Interestingly, there appears to be a subset of ALH (lesions which are pure ALH, demonstrating radiographic-pathologic concordance and no associated high-risk lesions found on core needle biopsy) in which the incidence of synchronous carcinoma is low $(\leq 3 \%$; $[10,11])$. Metachronous breast cancer develops subsequent to the initial $\mathrm{AH}$, potentially out 25 years or more [5], and may occur in either breast (Table 2). Whereas synchronous breast cancer is more commonly DCIS (Table 1), metachronous breast cancers are more often invasive carcinoma (Table 2), suggesting a range of carcinogenic influences for the genomic changes in AH. Atypical hyperplasias are commonly estrogen receptor positive [12], and treatment with antiestrogens may prevent the development of metachronous breast cancer within the remaining normal breast tissue [13]. This indicates that at least one important molecular characteristic of AH (ER positivity) is an indicator of the responsiveness of the remaining normal tissue to systemic therapy. An understanding of the molecular characteristics of these high-risk lesions may therefore clarify the role of $\mathrm{AH}$ in breast carcinogenesis, as well as to promote identification of new targets for the development of drugs for breast cancer prevention.

To further define the genomic changes of $\mathrm{AH}$, a comprehensive review of the literature was conducted to include all references describing numerical chromosomal changes, structural chromosomal changes, epigenetic changes, and changes in gene expression in atypical ductal and atypical lobular hyperplasia of the breast. The relationship of these genomic changes to those of associated synchronous breast cancer, and to the development of metachronous breast cancer, is discussed. A model summarizing the developmental pathways of $\mathrm{AH}$ is described.

Table 1 Incidence and characteristics of synchronous carcinoma with atypical hyperplasia

\begin{tabular}{|c|c|c|c|c|c|c|}
\hline $\begin{array}{l}\text { Primary atypical } \\
\text { hyperplasia }\end{array}$ & $\begin{array}{l}\text { Number of AH cases } \\
\text { excised }\end{array}$ & $\begin{array}{l}\text { Overall } \\
\text { carcinoma }\end{array}$ & $\begin{array}{l}\text { Invasive } \\
\text { carcinoma }\end{array}$ & $\begin{array}{l}\text { Ductal carcinoma } \\
\text { in situ }\end{array}$ & Risk factors & References \\
\hline $\mathrm{ADH}$ & 62 cases & $\begin{array}{l}9 \text { cases } \\
(14.5 \%)\end{array}$ & 2 cases $(3.2 \%)$ & 7 cases $(11.3 \%)$ & $\begin{array}{l}\text { Personal/family history } \\
\text { breast cancer }\end{array}$ & {$[60]$} \\
\hline ALH & 73 & $13(17.8 \%)$ & $5(6.8 \%)$ & $8(11.0 \%)$ & & {$[61]$} \\
\hline $\mathrm{ADH}$ & 104 & $22(21.2 \%)$ & $3(2.9 \%)$ & $19(18.3 \%)$ & & {$[62]$} \\
\hline $\mathrm{ADH}$ & 76 & $21(27.6 \%)$ & $3(3.9 \%)$ & $18(23.7 \%)$ & & {$[63]$} \\
\hline $\mathrm{ADH}$ & 61 & $19(31.2 \%)$ & $5(8.2 \%)$ & $14((23.0 \%)$ & & {$[64]$} \\
\hline ALH & 97 & $21(21.6 \%)$ & $6(6.2 \%)$ & $15(15.5 \%)$ & & {$[65]$} \\
\hline ADH (9 gauge) & 74 & $16(21.6 \%)$ & $2(2.7 \%)$ & $14(18.9 \%)$ & & {$[66]$} \\
\hline $\mathrm{ADH}$ & 101 & $20(19.8 \%)$ & $3(3.0 \%)$ & $17(16.8 \%)$ & Number of ADH foci & {$[67]$} \\
\hline $\mathrm{ADH}$ & 65 & $11(16.9 \%)$ & $5(7.7 \%)$ & $6(9.2 \%)$ & Increasing age & {$[68]$} \\
\hline ALH & 40 & $11(27.5 \%)$ & $4(10.0 \%)$ & $7(17.5 \%)$ & & [69] \\
\hline Mean & & $21.97 \% \pm 1.7$ & $5.47 \% \pm 0.84$ & $16.52 \% \pm 1.55$ & & \\
\hline
\end{tabular}


Table 2 Risk and incidence of metachronous breast carcinoma with atypical hyperplasia

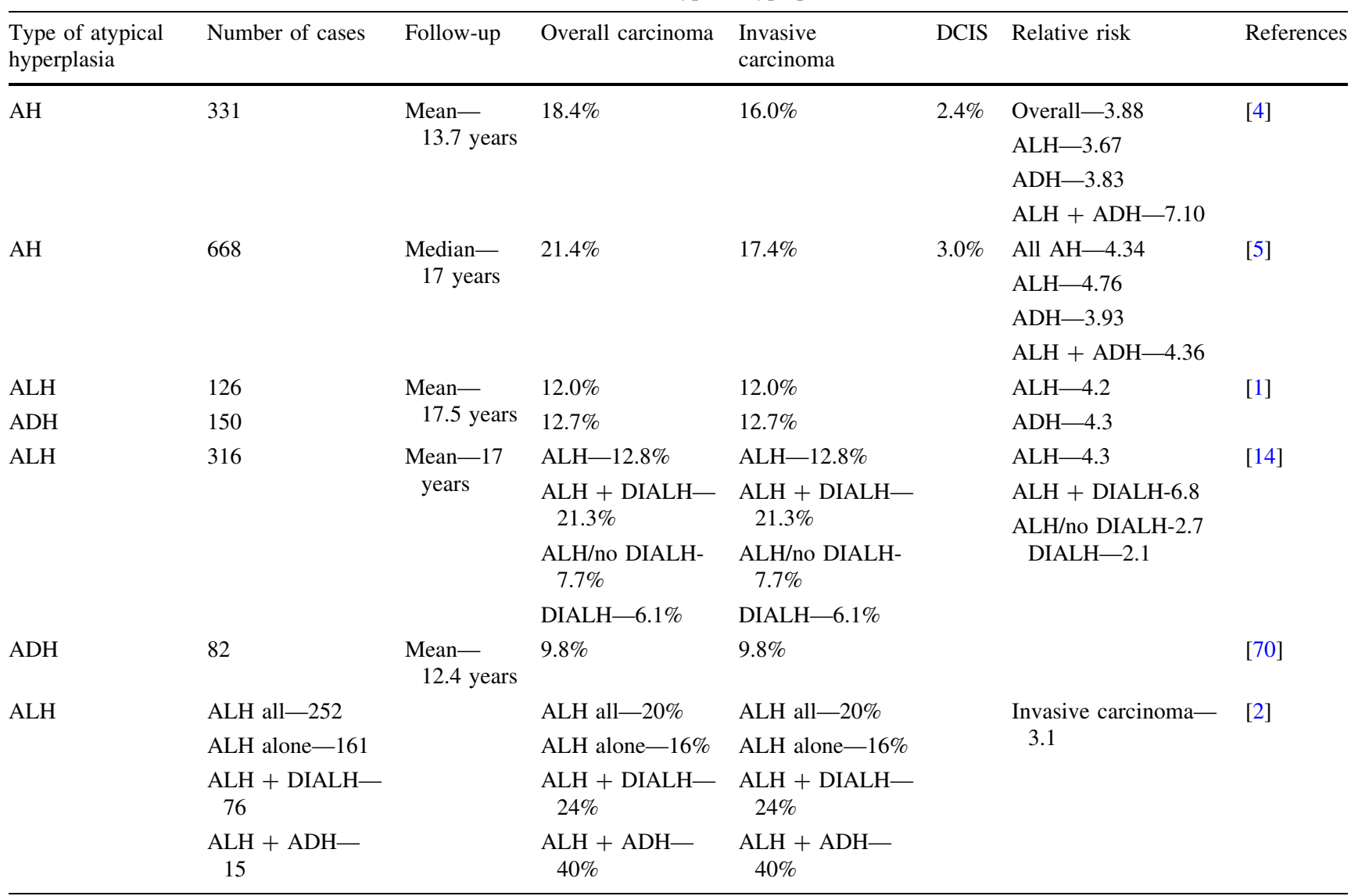

\section{Methods}

\section{Literature search and criteria for identification of tissue specimens}

A literature search was conducted through PubMed and cross references to identify all reports of atypical ductal hyperplasia, atypical lobular hyperplasia, or simply atypical hyperplasia of the breast which described studies of molecular changes in four genomic categories: numerical chromosomal changes, structural chromosomal changes, DNA methylation, or gene expression studies (see respective Tables below for references describing methods of analyses). The criteria for diagnosis of ADH and ALH are as previously described [1, 14, 15]. Proliferative epithelium with atypia, such as that acquired through random periareolar fine needle aspirate, or through breast ductal lavage, was also included. The presence of an in situ or invasive carcinoma associated with the $\mathrm{AH}$ lesion (such as that removed with an initial excisional biopsy) is noted, and these are referred to as being "synchronous" to indicate they occur at the same time as the primary lesion. This is in contrast to "metachronous" carcinomas which occurred at a later date and in either the ipsilateral or contralateral breast. Molecular changes in an associated breast carcinoma, either in situ or invasive, are included when available; however molecular changes in associated benign lesions such as ductal hyperplasia without atypia, flat epithelial atypia (FEA), or lobular carcinoma in situ (LCIS) are not described, and lobular neoplasia is included only if specific molecular changes in an associated ALH are described.

\section{Results and discussion}

\section{Numerical chromosomal changes in atypical hyperplasia}

Studies examining chromosomal content by FISH, DNA content, or nuclear morphometry of ADH and ALH showed gains or losses of whole chromosomes compared to 
Table 3 Numerical chromosomal abnormalities in atypical hyperplasia

\begin{tabular}{|c|c|c|c|c|c|c|}
\hline Chromosome & Alteration & Normal breast & Atypical hyperplasia & DCIS & Invasive carcinoma & References \\
\hline 1 & $\begin{array}{l}\text { Chromosome } \\
\text { copy number- } \\
\text { FISH }\end{array}$ & Normal compliment & $\mathrm{ALH}-$ no gain or loss & Gain $100 \%$ & Gain $100 \%$ & {$[20]$} \\
\hline 1 & Ploidy, FISH & Normal content & $\begin{array}{l}\mathrm{ADH} \text {-aneusomy, } \\
100.0 \%\end{array}$ & $\begin{array}{l}\text { Gain, } 72.7 \% \\
\text { Loss, } 9.1 \%\end{array}$ & Gain, $87.5 \%$ & [71] \\
\hline 1 & $\begin{array}{l}\text { Chromosome } \\
\text { copy number, } \\
\text { FISH }\end{array}$ & $\begin{array}{l}\text { Signal number- } \\
\quad 1.14\end{array}$ & $\begin{array}{l}\mathrm{ADH} \text {-increased copy } \\
\text { number, signal } \\
\text { number } 1.50\end{array}$ & $\begin{array}{l}\text { Increased, copy } \\
\text { number, signal } \\
\text { number } 1.95\end{array}$ & $\begin{array}{l}\text { Increased copy } \\
\text { number, signal } \\
\text { number } 1.74\end{array}$ & {$[23]$} \\
\hline 16 & $\begin{array}{l}\text { Chromosome } \\
\text { copy number- } \\
\text { FISH }\end{array}$ & Borderline loss & ALH—gain, $50 \%$ & Gain, $100 \%$ & Gain, $100 \%$ & {$[20]$} \\
\hline 17 & $\begin{array}{l}\text { Chromosome } \\
\text { copy number- } \\
\text { FISH }\end{array}$ & Normal compliment & $\begin{array}{l}\text { ALH_borderline loss, } \\
50 \%\end{array}$ & True gain, $100 \%$ & True gain, $100 \%$ & {$[20]$} \\
\hline 17 & Ploidy, FISH & Normal content & $\mathrm{ADH}-$ no loss or gain & $\begin{array}{l}\text { Gain, } 45.5 \% \\
\text { Loss, } 45.5 \%\end{array}$ & Gain, $50.0 \%$ & [71] \\
\hline 18 & $\begin{array}{l}\text { Chromosome } \\
\text { copy number- } \\
\text { FISH }\end{array}$ & Borderline loss & $\begin{array}{l}\text { ALH_borderline loss } \\
50 \%\end{array}$ & Gain, $100 \%$ & $\begin{array}{l}\text { Borderline gain, } \\
100 \%\end{array}$ & {$[20]$} \\
\hline $\begin{array}{l}\text { Chromosomes } \\
8,11\end{array}$ & FISH & & $\begin{array}{l}\text { Nipple aspirate fluid } \\
\text { mild atypia-20\% } \\
\text { aneusomy }\end{array}$ & & & {$[72]$} \\
\hline $\begin{array}{r}\text { Chromosomes } \\
1,8,11 \text { or } 17 .\end{array}$ & FISH & Disomy-100\% & $\begin{array}{l}\text { Nipple aspirate fluid, } \\
\text { marked atypia- } \\
100 \% \text { aneusomy }\end{array}$ & & $\begin{array}{l}\text { Nipple aspirate fluid, } \\
\text { malignant, } 100 \% \\
\text { aneusomy }\end{array}$ & {$[72]$} \\
\hline $\begin{array}{l}\text { Chromosomes } \\
7-12,17,18, \mathrm{X}\end{array}$ & $\begin{array}{l}\text { Chromosomal } \\
\text { aberrations, } \\
\text { cytologic, FISH }\end{array}$ & $\begin{array}{l}40 \% \text { of non- } \\
\text { proliferative } \\
\text { lesions }\end{array}$ & $\mathrm{ADH}-100 \%$ & & $\begin{array}{l}100 \% \text { (includes } \\
\text { DCIS) }\end{array}$ & {$[16]$} \\
\hline $\begin{array}{l}\text { Chromosomes } \\
1,7,8,16, \\
17, \mathrm{X}\end{array}$ & $\begin{array}{l}\text { Chromosome } \\
\text { copy number- } \\
\text { FISH }\end{array}$ & & $\begin{array}{l}\text { ADH—no gains or } \\
\text { losses } \\
\text { ALH, chromosome } 8 \text {, } \\
3 \% \text { triploid }\end{array}$ & $70 \%$ aneuploidy & $100 \%$ aneuploidy & [73] \\
\hline \multirow{7}{*}{$\begin{array}{l}\text { Nucleus- } \\
\text { nuclear } \\
\text { morphometry }\end{array}$} & Area & $\begin{array}{l}\text { Non-proliferative } \\
25.5\end{array}$ & $\mathrm{AH}-37.4$ & 47.9 & 54.9 & {$[74]$} \\
\hline & Perimeter & $\begin{array}{l}\text { Non-proliferative } \\
20.6\end{array}$ & $\mathrm{AH}-24.3$ & 27.2 & 29.4 & {$[74]$} \\
\hline & $\begin{array}{r}\text { Maximum } \\
\text { diameter }\end{array}$ & $\begin{array}{l}\text { Non-proliferative } \\
7.3\end{array}$ & $\mathrm{AH}-8.52$ & 9.6 & 10.3 & {$[74]$} \\
\hline & $\begin{array}{l}\text { Minimum } \\
\text { diameter }\end{array}$ & $\begin{array}{l}\text { Non-proliferative } \\
5.1\end{array}$ & $\mathrm{AH}-6.0$ & 6.9 & 7.4 & {$[74]$} \\
\hline & Large dark areas & $\begin{array}{l}\text { Non-proliferative } \\
0.022\end{array}$ & $\mathrm{AH}-0.084$ & 0.103 & 0.099 & {$[74]$} \\
\hline & Large light areas & $\begin{array}{l}\text { Non-proliferative } \\
0.009\end{array}$ & $\mathrm{AH}-0.038$ & 0.049 & 0.075 & {$[74]$} \\
\hline & Total stain & $\begin{array}{l}\text { Non-proliferative } \\
12.52\end{array}$ & $\mathrm{AH}-12.38$ & 23.73 & 19.72 & [74] \\
\hline DNA content & & Normal diploid & $\begin{array}{l}\text { ADH—diploid, 33\% } \\
\text { Type III histogram, } \\
33.3 \% \\
\text { Aneuploid, } 33.3 \% \\
\text { ALH—diploid, } 100 \%\end{array}$ & & & {$[75]$} \\
\hline DNA content & $\begin{array}{l}\text { Nuclear DNA } \\
\text { histogram }\end{array}$ & Diploid & $\begin{array}{l}\text { ADH-Type III/IV } \\
\text { histogram, 38.1\% } \\
\text { ALH-diploid }\end{array}$ & & & [76] \\
\hline
\end{tabular}


Table 3 continued

\begin{tabular}{|c|c|c|c|c|c|c|}
\hline Chromosome & Alteration & Normal breast & Atypical hyperplasia & DCIS & Invasive carcinoma & References \\
\hline DNA content & & $\begin{array}{l}\text { Hyperplasia without } \\
\text { atypia-diploid }\end{array}$ & Aneuploid, $33.3 \%$ & Aneuploid, $78.2 \%$ & & [19] \\
\hline DNA content & Aneuploidy & & $\mathrm{AH}$-aneuploid, $30.8 \%$ & Aneuploid, 33.3\% & Aneuploid, $88.5 \%$ & [77] \\
\hline DNA ploidy & $\begin{array}{l}\text { Cytometric } \\
\text { assessment }\end{array}$ & $\begin{array}{l}\text { Intraductal } \\
\text { proliferation } \\
\text { without atypia- } \\
\text { euploid }\end{array}$ & $\begin{array}{l}\mathrm{ADH}-43 \% \\
\text { aneuploidy }\end{array}$ & $\begin{array}{c}71.4 \%-84.4 \% \\
\text { aneuploidy }\end{array}$ & $\begin{array}{l}54.1 \%-95.6 \% \\
\text { aneuploidy }\end{array}$ & {$[78]$} \\
\hline $\begin{array}{l}\text { DNA } \\
\text { aneuploidy }\end{array}$ & DNA histogram & & $\mathrm{AH}$-aneuploidy, $71 \%$ & Aneuploidy, $71 \%$ & & {$[6]$} \\
\hline $\begin{array}{l}\text { DNA } \\
\text { aneuploidy }\end{array}$ & DNA Index & $\begin{array}{l}\text { Non-proliferative- } \\
25 \% \text { aneuploidy }\end{array}$ & $\begin{array}{l}\text { Hyperplasia with } \\
\text { atypia—aneuploidy } \\
32 \%\end{array}$ & & & [79] \\
\hline $\begin{array}{l}\text { Nuclear } \\
\text { morphometry }\end{array}$ & Nuclear area & 13.13 & $\mathrm{AH}-24.25$ & $\begin{array}{l}\text { Cribriform-16.16 } \\
\text { Comedo-40.23 }\end{array}$ & 41.30 & [17] \\
\hline $\begin{array}{l}\text { Nuclear } \\
\text { morphometry }\end{array}$ & $\begin{array}{l}\text { Nuclear } \\
\text { abnormality }\end{array}$ & 0.644 & $\mathrm{AH}-2.261$ & $\begin{array}{l}\text { Cribriform- }-0.918 \\
\text { Comedo- } 2.710\end{array}$ & 1.265 & [17] \\
\hline Monoclonality & $\begin{array}{l}\text { X-chromosome } \\
\text { inactivation } \\
\text { assay }\end{array}$ & $0 \%$ monoclonal & $\begin{array}{l}\mathrm{AH}-51.3 \% \\
\text { monoclonal }\end{array}$ & $100 \%$ monoclonal & & {$[21]$} \\
\hline $\begin{array}{l}\text { Nucleolar } \\
\text { organizer } \\
\text { regions }\end{array}$ & Ag-NOR-IHC & 6.0 & $\begin{array}{l}\mathrm{ADH}-8.8 \\
\mathrm{ALH}-8.6\end{array}$ & 9.0 & 17.7 & [18] \\
\hline $\begin{array}{l}\text { DNA } \\
\text { quantitation }\end{array}$ & Aneuploidy & Euploid (NABT) & $\begin{array}{l}\mathrm{AEH}-\text { aneuploidy } \\
50 \%\end{array}$ & & Aneuploidy 50\% & {$[80]$} \\
\hline Mitotic figures & Mitoses/HPF & $\begin{array}{l}3.5 \text { (proliferative } \\
\text { disease without } \\
\text { atypia) }\end{array}$ & $\mathrm{ADH}-6.7$ & $\begin{array}{l}\text { DCIS-26.5 } \\
\text { DCIS in } \\
\text { infiltrating } \\
\text { carcinoma-51.3 }\end{array}$ & & [81] \\
\hline $\begin{array}{l}\text { Chromosomal } \\
\text { abnormalities }\end{array}$ & Cytogenic, FISH & & $\begin{array}{l}\text { AEH—diploid with } \\
\text { structural aberrations }\end{array}$ & & & {$[82]$} \\
\hline
\end{tabular}

$N A B T$ normal breast tissue adjacent to cancer, IHC immunohistochemistry, FISH fluorescent in situ hybridization, AEH atypical epithelial hyperplasia

normal breast tissue, indicating aneuploidy is a prominent feature of atypical hyperplasia (Table 3). The chromosomal changes seen in atypical hyperplasias are similar to those present in breast cancer [16-18], and are consistent with the proposal that $\mathrm{AHs}$ are preneoplastic lesions and part of a continuum in the steps toward breast cancer $[19,20]$. Mariuzzi et al. [17] examined the nuclear chromatin pattern in $\mathrm{AH}$ and found drastic changes in karyometric features, with these changes similar to those seen in comedo DCIS. Others have noted a high incidence of monoclonality (51.3\%) in ADH [21], and an abnormal DNA content [6], consistent with neoplastic transformation. Eriksson et al. [22] considered the DNA cytometric findings in atypical hyperplasias to strongly indicate that, already at this early stage, complex nuclear alterations have occurred. Further evidence for this relationship is found in the studies of Cummings et al. [23] who examined specimens containing both AH and DCIS and found concordance in chromosome 1 aneuploidy between these lesions. They considered these findings to support the concept that benign proliferative breast disease is a biological precursor of in situ and invasive ductal carcinoma, the early histological changes possibly indicating a field effect with further genetic changes required for the development of a malignant phenotype [23].

Aneuploidy is an important indicator of chromosomal instability [24], resulting in significant deregulation of the transcriptome [25], aneuploidy-induced stresses [26], and contributing to further progression in the carcinogenic pathway. The causes of aneuploidy in $\mathrm{AH}$ are not clear; however, alterations in multiple genes known to contribute to aneuploidy have been observed in $\mathrm{AH}$ (Tables 4, 5, 6). 
Table 4 Structural chromosomal abnormalities in atypical hyperplasia

\begin{tabular}{|c|c|c|c|c|c|c|c|}
\hline Chromosome & Gene & Alteration & $\begin{array}{l}\text { Normal } \\
\text { breast }\end{array}$ & $\begin{array}{l}\text { Atypical } \\
\text { hyperplasia }\end{array}$ & DCIS & $\begin{array}{l}\text { Invasive } \\
\text { carcinoma }\end{array}$ & References \\
\hline $1 \mathrm{p} 32$ & $M Y C 1$ & MSI/LOH & & $8.3 \%$ & & & {$[33]$} \\
\hline $1 \mathrm{q}$ & & $\mathrm{CGH}$ & & $\mathrm{ADH}-$ gain $11.1 \%$ & & & {$[35]$} \\
\hline $1 \mathrm{q}$ & & $\begin{array}{l}\text { Chromosome } \\
\text { copy number, } \\
\text { CGH }\end{array}$ & & $\mathrm{ADH}$-gain $33.3 \%$ & Gain, $60 \%$ & Gain, $80 \%$ & {$[83]$} \\
\hline $\begin{array}{l}\text { 1q32-42/D1S549, } \\
\text { D1S213 }\end{array}$ & & $\begin{array}{l}\mathrm{LOH} \\
\quad \text { (proportion) }\end{array}$ & $2 \%$ & $\begin{array}{l}\text { ADH with cancer, } \\
29 \%\end{array}$ & $52 \%$ & $44 \%$ & {$[32]$} \\
\hline 1q32-42/D1S549 & & MSI/LOH & & $\mathrm{AH}-25.0 \%$ & & & {$[33]$} \\
\hline 1q32-qter & & $\mathrm{CGH}$ & & $\begin{array}{l}\text { ADH_high-level } \\
\text { amplification }\end{array}$ & & & [7] \\
\hline $2 \mathrm{p} 11.2$ & & $\mathrm{CGH}$ & & ALH—gains, $50 \%$ & & & {$[84]$} \\
\hline \multirow[t]{2}{*}{ 2q35/D2S362 } & & $\mathrm{LOH}$ & & $\begin{array}{l}\text { ADH non- } \\
\text { cancerous } \\
\text { breast—none }\end{array}$ & $\begin{array}{l}\text { Non- } \\
\text { comedo- } \\
6 \%\end{array}$ & & {$[85]$} \\
\hline & & & & $\begin{array}{l}\text { ADH cancerous } \\
\text { breast }-6 \%\end{array}$ & Comedo-9\% & & \\
\hline $3 p$ & rhoA, $c d c 25 A$ & $\mathrm{CGH}$ & & $\mathrm{ADH}$-gains & & & {$[83]$} \\
\hline 3p24/D3S1298 & & MSI/LOH & & $\mathrm{AH}-8.3 \%$ & & & {$[33]$} \\
\hline 3 p22ter & & $\mathrm{CGH}$ & & ADH gain, $67 \%$ & & Gain, $60 \%$ & {$[83]$} \\
\hline $3 q 11-q 21$ & & $\mathrm{CGH}$ & & ADH loss, $11.1 \%$ & & & {$[35]$} \\
\hline $5 p$ & & $\mathrm{CGH}$ & & Gain & Gain & Gain & [7] \\
\hline $5 \mathrm{p} 14$ & & $\mathrm{CGH}$ & & $\begin{array}{l}\text { ADH_high-level } \\
\text { amplification }\end{array}$ & & & [7] \\
\hline $5 q 32-33.1$ & $C S F 1 R$ & $\mathrm{CGH}$ & & ALH—gain & & & [84] \\
\hline $6 \mathrm{q}$ & & $\begin{array}{l}\text { Chromosomal } \\
\text { imbalance, } \\
\text { CGH }\end{array}$ & & ALH—gain, $36 \%$ & Gain, $22 \%$ & Gain, $2 \%$ & {$[86]$} \\
\hline \multirow[t]{2}{*}{ 6qter/D6S417 } & & $\mathrm{LOH}$ & & $\begin{array}{l}\text { ADH non- } \\
\text { cancerous } \\
\text { breast }-6 \%\end{array}$ & $\begin{array}{l}\text { Non- } \\
\text { comedo- } \\
17 \%\end{array}$ & & {$[85]$} \\
\hline & & & & $\begin{array}{l}\text { ADH cancerous } \\
\text { breast }-9 \%\end{array}$ & $\begin{array}{l}\text { Comedo- } \\
11 \%\end{array}$ & & \\
\hline $6 \mathrm{~g} 21$ ter & & $\mathrm{CGH}$ & & $\mathrm{ADH}$-gain, $33.3 \%$ & Gain, $40 \%$ & Gain, $60 \%$ & [83] \\
\hline 6q27-qter & SEN6 & $\begin{array}{l}\text { FISH, } \\
\text { cytogenetic }\end{array}$ & & $\begin{array}{l}\mathrm{ADH}-\text {-large } \\
\text { deletion present }\end{array}$ & & & [87] \\
\hline 7p11.2-p11.1 & & $\mathrm{CGH}$ & & ALH—Loss, $83.3 \%$ & & & {$[84]$} \\
\hline $7 \mathrm{p} 12-15$ & $E G F R$ & $\begin{array}{l}\text { Microsatellite } \\
\text { analysis }\end{array}$ & $30.0 \%$ & $\begin{array}{l}\text { ADH of cancer } \\
\text { subject }-80 \%\end{array}$ & $100.0 \%$ & $100.0 \%$ & {$[88]$} \\
\hline $7 \mathrm{p} 22$-qter & & $\mathrm{CGH}$ & & $\begin{array}{l}\text { ADH-high-level } \\
\text { amplification }\end{array}$ & & & [7] \\
\hline $7 q 35$ ter & & $\mathrm{CGH}$ & & $\mathrm{ADH}$-gain, $33.3 \%$ & & Gain, $40 \%$ & [83] \\
\hline $8 \mathrm{p}$ & $\begin{array}{l}\text { NRG1 (just distal to } \\
\text { region) }\end{array}$ & $\mathrm{CGH}$ & & $\mathrm{ADH}-\mathrm{loss}$ & Loss & Loss & [7] \\
\hline 8p/D8S339 & & $\mathrm{LOH}$ & & $\begin{array}{l}\text { ADH with cancer- } \\
\geq 25 \%\end{array}$ & & $\geq 35 \%$ & {$[34]$} \\
\hline 8p12-pter & & $\mathrm{CGH}$ & & ADH-Loss, $11.1 \%$ & & & {$[35]$} \\
\hline $8 \mathrm{q}$ & & $\mathrm{CGH}$ & & $\begin{array}{l}\text { ADH_high-level } \\
\text { amplification }\end{array}$ & & & [7] \\
\hline 8q21-qter & & $\mathrm{CGH}$ & & $\mathrm{ADH}$-gain, $11.1 \%$ & & & {$[35]$} \\
\hline $8 q 24$ & $M Y C$ & & & ADH—gain, $66.0 \%$ & Gain, $60 \%$ & Gain, $80 \%$ & {$[83]$} \\
\hline $8 \mathrm{q} 24$ & MTSS1; MYC & AI & $0.0 \%$ & $\mathrm{ADH}-35 \%$ & $29 \%$ & $13 \%-37 \%$ & [89] \\
\hline
\end{tabular}


Table 4 continued

\begin{tabular}{|c|c|c|c|c|c|c|c|}
\hline Chromosome & Gene & Alteration & $\begin{array}{l}\text { Normal } \\
\text { breast }\end{array}$ & $\begin{array}{l}\text { Atypical } \\
\text { hyperplasia }\end{array}$ & DCIS & $\begin{array}{l}\text { Invasive } \\
\text { carcinoma }\end{array}$ & References \\
\hline 9p/D9S157 & & $\mathrm{LOH}$ & & $\begin{array}{l}\text { ADH non- } \\
\text { cancerous } \\
\text { breast- }-8 \%\end{array}$ & $\begin{array}{l}\text { Non- } \\
\text { comedo- } \\
10 \% \\
\text { Comedo- } \\
11 \%\end{array}$ & & {$[85]$} \\
\hline $9 \mathrm{p} 21$ & & AI & $5 \%$ & $\mathrm{ADH}-8 \%$ & $16 \%$ & $11 \%-28 \%$ & [89] \\
\hline $10 \mathrm{q} 25$ ter & & $\mathrm{CGH}$ & & $\mathrm{ADH}$-gain, $33.3 \%$ & Gain, $40 \%$ & Gain, $80 \%$ & [83] \\
\hline $10 q 26$ & & $\mathrm{CGH}$ & & $\begin{array}{l}\text { ADH-high-level } \\
\text { amplification }\end{array}$ & & & [7] \\
\hline \multirow[t]{2}{*}{ 11p15/D11S988 } & & $\mathrm{LOH}$ & & $\begin{array}{l}\text { ADH non- } \\
\text { cancerous } \\
\text { breast-15\% }\end{array}$ & $\begin{array}{l}\text { Non- } \\
\text { comedo- } \\
18 \%\end{array}$ & & {$[85]$} \\
\hline & & & & $\begin{array}{c}\text { ADH cancerous } \\
\text { breast- }-38 \%\end{array}$ & $\begin{array}{l}\text { Comedo- } \\
19 \%\end{array}$ & & \\
\hline $11 \mathrm{p} 15$ & THOI & $\begin{array}{l}\mathrm{LOH} \\
\quad \text { (proportion) }\end{array}$ & & $\begin{array}{l}\text { ADH with cancer- } \\
8 \%\end{array}$ & $37 \%$ & $28 \%$ & {$[32]$} \\
\hline $11 q 12-13$ & & $\mathrm{CGH}$ & & $\mathrm{ADH}$-gain, $11.1 \%$ & & & {$[35]$} \\
\hline 11q13(PYGM) & $P Y G M$ & $\mathrm{LOH}$ & None & $\mathrm{ADH}-8.5 \%$ & $27.6 \%$ & & {$[90]$} \\
\hline $11 \mathrm{q} 13$ & INT-2 or PYGM & $\mathrm{LOH}$ & & ALH- $-10.5 \%$ & & $33.3 \%$ & [91] \\
\hline $11 \mathrm{q} 13$ & & $\mathrm{CGH}$ & & ADH—gain, $33.3 \%$ & Gain, $40 \%$ & Gain, $80 \%$ & {$[83]$} \\
\hline $11 \mathrm{q} 13.1$ & & AI & $0.0 \%$ & $\mathrm{ADH}-8 \%$ & $9 \%$ & $21 \%-30 \%$ & [89] \\
\hline $\begin{array}{l}\text { 11q13/11q22-23/ } \\
\text { D11s1818, } \\
\text { D11s1819 }\end{array}$ & PYGM & $\begin{array}{l}\mathrm{LOH} \\
\quad \text { (proportion) }\end{array}$ & & $\begin{array}{l}\text { ADH with cancer- } \\
11 \%\end{array}$ & $35 \%$ & $57 \%$ & {$[32]$} \\
\hline $11 \mathrm{q} 23.3$ & & AI & $4 \%$ & $\mathrm{ADH}-8 \%$ & $21 \%$ & $25 \%-50 \%$ & [89] \\
\hline $11 \mathrm{q} 24$ ter & & $\mathrm{CGH}$ & & ADH—gain, $33.3 \%$ & Gain, $20 \%$ & Gain, $40 \%$ & {$[83]$} \\
\hline 12p13-pter & & $\mathrm{CGH}$ & & $\begin{array}{l}\text { ADH-high-level } \\
\text { amplification }\end{array}$ & & & [7] \\
\hline $12 \mathrm{q} 24$ & & $\mathrm{CGH}$ & & $\mathrm{ADH}$-gain, $33.3 \%$ & Gain, $20 \%$ & Gain, $80 \%$ & {$[83]$} \\
\hline $13 q 11-22$ & & $\mathrm{CGH}$ & & $\mathrm{ADH}-\mathrm{loss}, 66 \%$ & Loss-100\% & Loss- $-100 \%$ & {$[83]$} \\
\hline \multirow[t]{2}{*}{ 13q13/D13S137 } & & $\mathrm{LOH}$ & & $\begin{array}{l}\text { ADH non- } \\
\text { cancerous } \\
\text { breast- }-13 \%\end{array}$ & $\begin{array}{l}\text { Non- } \\
\text { comedo- } \\
17 \%\end{array}$ & & {$[85]$} \\
\hline & & & & $\begin{array}{l}\text { ADH cancerous } \\
\text { breast }-9 \%\end{array}$ & $\begin{array}{l}\text { Comedo- } \\
13 \%\end{array}$ & & \\
\hline $13 q 32-q 34$ & & $\mathrm{CGH}$ & & $\begin{array}{l}\text { ADH_high-level } \\
\text { amplification }\end{array}$ & & & [7] \\
\hline $14 q 11.2-q 12$ & & $\mathrm{CGH}$ & & $\begin{array}{l}\text { ADH-high-level } \\
\text { amplification }\end{array}$ & & & [7] \\
\hline \multirow[t]{2}{*}{ 14q24/D14S62 } & & $\mathrm{LOH}$ & & $\begin{array}{l}\text { ADH non- } \\
\text { cancerous } \\
\text { breast—none }\end{array}$ & $\begin{array}{l}\text { Non- } \\
\text { comedo- } \\
16 \%\end{array}$ & & {$[85]$} \\
\hline & & & & $\begin{array}{c}\text { ADH cancerous } \\
\text { breast }-12 \%\end{array}$ & $\begin{array}{l}\text { Comedo- } \\
18 \%\end{array}$ & & \\
\hline $14 q 32$ & & $\mathrm{CGH}$ & & ADH—gain, $33.3 \%$ & Gain, $20 \%$ & Gain, $40 \%$ & {$[83]$} \\
\hline $14 q 32.33$ & $A T K 1$ & $\mathrm{CGH}$ & & ALH- gain & & & {$[84]$} \\
\hline $15 q 23-25$ & $c-s r c-1$ & $\mathrm{CGH}$ & & $\mathrm{ADH}-$ gain, $67 \%$ & & & {$[83]$} \\
\hline $15 q 25$-qter & & $\mathrm{CGH}$ & & $\begin{array}{l}\text { ADH_high-level } \\
\text { amplification }\end{array}$ & & & [7] \\
\hline $15 q 26$ & & $\mathrm{CGH}$ & & ADH_-gain, $66.0 \%$ & Gain, $40 \%$ & Gain, $100 \%$ & [83] \\
\hline
\end{tabular}


Table 4 continued

\begin{tabular}{|c|c|c|c|c|c|c|c|}
\hline Chromosome & Gene & Alteration & $\begin{array}{l}\text { Normal } \\
\text { breast }\end{array}$ & $\begin{array}{l}\text { Atypical } \\
\text { hyperplasia }\end{array}$ & DCIS & $\begin{array}{l}\text { Invasive } \\
\text { carcinoma }\end{array}$ & References \\
\hline $16 \mathrm{p}$ & & $\begin{array}{l}\text { Chromosome } \\
\text { copy number, } \\
\text { CGH }\end{array}$ & & $\begin{array}{l}\text { ALH-loss, } 57 \% \\
\text { loss }\end{array}$ & Loss, $6 \%$ & $\begin{array}{l}\text { Loss, } 1 \%- \\
13 \%\end{array}$ & {$[86]$} \\
\hline $16 \mathrm{p}$ & & $\begin{array}{l}\text { Chromosome } \\
\text { copy number/ } \\
\text { CGH }\end{array}$ & & $\mathrm{ADH}$-gain, $33.3 \%$ & Gain, $80 \%$ & Gain, $100 \%$ & {$[83]$} \\
\hline $16 \mathrm{q}$ & & $\mathrm{LOH}$ & & $\begin{array}{l}\text { Atypical } \\
\text { hyperplasia-50\% }\end{array}$ & & $71.4 \%$ & {$[92]$} \\
\hline \multirow[t]{2}{*}{$16 \mathrm{q}$} & $\mathrm{CDH1}$ & $\mathrm{LOH}$ & & ALH- $-7.7 \%$ & & & [93] \\
\hline & & Mutation & & $\begin{array}{c}\text { ALH—frameshift } \\
\text { mutation, } 7.7 \%\end{array}$ & & & \\
\hline $16 \mathrm{q}$ & $\begin{array}{l}\text { Matrix } \\
\quad \text { metalloproteinase } \\
\text { 2, NME3 }\end{array}$ & $\mathrm{CGH}$ & & $\mathrm{ADH}-\mathrm{loss}, 33.3 \%$ & & & {$[83]$} \\
\hline $16 \mathrm{q}$ & & $\mathrm{CGH}$ & & ADH-loss, $55.5 \%$ & & & {$[35]$} \\
\hline $16 \mathrm{q}$ & & $\mathrm{CGH}$ & & ALH-loss, $36 \%$ & Loss, $17 \%$ & $\begin{array}{l}\text { Loss, } 25 \%- \\
67 \%\end{array}$ & {$[86]$} \\
\hline $16 q$ & $\begin{array}{l}\text { CDH1, E2F4, } \\
\text { WWOX }\end{array}$ & $\mathrm{CGH}$ & & $\mathrm{ADH}-\mathrm{loss}$ & Loss & Loss & [7] \\
\hline 16q/D16S413 & & $\mathrm{LOH}$ & & $\begin{array}{l}\text { Atypical ductal } \\
\text { hyperplasia- } \\
55.6 \%\end{array}$ & & & [94] \\
\hline 16q/D16S422 & CDH13 & $\mathrm{LOH}$ & & $\begin{array}{l}\text { ADH with cancer- } \\
\geq 25 \%\end{array}$ & & $\geq 35 \%$ & {$[34]$} \\
\hline $16 q 21-q 23.1$ & $\mathrm{CDH1}$ & $\mathrm{CGH}$ & & ALH-loss, $25 \%$ & & & {$[84]$} \\
\hline $\begin{array}{c}\text { 16q21-24/ } \\
\text { D16s265, } \\
\text { D16s402, } \\
\text { D16s413, } \\
\text { D16s512 }\end{array}$ & & $\begin{array}{l}\mathrm{LOH} \\
\quad \text { (proportion) }\end{array}$ & $2 \%$ & $\mathrm{ADH}-52 \%$ & $63 \%$ & $78 \%$ & {$[32]$} \\
\hline $17 p$ & & $\mathrm{CGH}$ & & $\mathrm{ADH}-\operatorname{loss} 22.2 \%$ & & & {$[35]$} \\
\hline $17 p$ & P53 & $\mathrm{CGH}$ & & $\mathrm{ADH}-\mathrm{loss}$ & Loss & Loss & [7] \\
\hline 17p13/D17S796 & Close to P53 & $\mathrm{LOH}$ & & $\begin{array}{l}\mathrm{ADH} \text { in normal } \\
\text { adjacent to } \\
\text { cancer-33.3\% }\end{array}$ & $100 \%$ & $100 \%$ & {$[95]$} \\
\hline \multirow[t]{2}{*}{ 17p13/D17S960 } & P53 candidate gene & $\mathrm{LOH}$ & & $\begin{array}{l}\text { ADH non- } \\
\text { cancerous } \\
\text { breast- }-11 \%\end{array}$ & $\begin{array}{l}\text { Non- } \\
\text { comedo- } \\
31 \%\end{array}$ & & [85] \\
\hline & & & & $\begin{array}{l}\text { ADH cancerous } \\
\text { breast }-8 \%\end{array}$ & $\begin{array}{l}\text { Comedo- } \\
37 \%\end{array}$ & & \\
\hline $17 \mathrm{p} 13.1$ & TP53 & $\begin{array}{l}\text { Microsatellite } \\
\text { alterations }\end{array}$ & & $\mathrm{AH}-16.6 \%$ & & & {$[33]$} \\
\hline $\begin{array}{l}\text { 17p13.1/D17s796, } \\
\text { D17s525 }\end{array}$ & TP53 & $\begin{array}{l}\mathrm{LOH} \\
\quad \text { (proportion) }\end{array}$ & & $\begin{array}{l}\text { ADH with cancer- } \\
6 \%\end{array}$ & $42 \%$ & $59 \%$ & {$[32]$} \\
\hline P53 & $T P 53$ & Mutations & & $\begin{array}{l}\mathrm{ADH} \text {-mutations in } \\
50 \%\end{array}$ & & & {$[46]$} \\
\hline 17p13.2/D17S796 & Within $2 \mathrm{cM}$ of $\mathrm{p} 53$ & $\mathrm{LOH}$ & & $\mathrm{ADH}-25.0 \%$ & & & [94] \\
\hline \multirow[t]{2}{*}{$17 \mathrm{q}$} & $\begin{array}{l}\text { HER-2/neu, GRB7, } \\
\text { TBX2, STARD3, } \\
\text { MLN64/ }\end{array}$ & $\mathrm{CGH}$ & & $\mathrm{ADH}$-gain & & & [7] \\
\hline & $\begin{array}{l}\text { CAB1, and } \\
\text { ESTIMAGE68400 }\end{array}$ & & & & & & \\
\hline
\end{tabular}


Table 4 continued

\begin{tabular}{|c|c|c|c|c|c|c|c|}
\hline Chromosome & Gene & Alteration & $\begin{array}{l}\text { Normal } \\
\text { breast }\end{array}$ & $\begin{array}{l}\text { Atypical } \\
\text { hyperplasia }\end{array}$ & DCIS & $\begin{array}{l}\text { Invasive } \\
\text { carcinoma }\end{array}$ & References \\
\hline \multirow[t]{2}{*}{ 17q11/NF1 } & & $\mathrm{LOH}$ & & $\begin{array}{l}\text { ADH non- } \\
\text { cancerous } \\
\text { breast- }-14 \%\end{array}$ & $\begin{array}{l}\text { Non- } \\
\text { comedo- } \\
27 \%\end{array}$ & & {$[85]$} \\
\hline & & & & $\begin{array}{l}\text { ADH cancerous } \\
\text { breast-10\% }\end{array}$ & $\begin{array}{l}\text { Comedo- } \\
15 \%\end{array}$ & & \\
\hline $17 \mathrm{q} 21$ & & AI & $0.0 \%$ & $\mathrm{ADH}-7 \%$ & $30 \%$ & $19 \%-27 \%$ & [89] \\
\hline 17q21/D17S579 & Region of $B R C A 1$ & MSI/LOH & & $\mathrm{AH}-8.3 \%$ & & & {$[33]$} \\
\hline D17S8000 & $B R C A 1$ & $\mathrm{LOH}$ & & $\mathrm{ADH} \geq 25 \%$ & & & {$[34]$} \\
\hline 20p11.2-p13 & & $\mathrm{CGH}$ & & $\begin{array}{l}\text { ADH_high-level } \\
\text { amplification }\end{array}$ & & & [7] \\
\hline $20 \mathrm{q}$ & $\begin{array}{l}\text { AIB1, TFAP2C, } \\
\text { STK15 }\end{array}$ & $\mathrm{CGH}$ & & $\mathrm{ADH}$-gain & Gain & Gain & [7] \\
\hline $20 q$ & & $\begin{array}{l}\text { Chromosomal } \\
\text { copy number } \\
\text { alterations/ } \\
\text { CGH }\end{array}$ & None & $\begin{array}{l}\text { ADH -amplified } \\
100 \%\end{array}$ & $\begin{array}{l}100 \% \text { show } \\
\text { amplification }\end{array}$ & $\begin{array}{l}100 \% \text { show } \\
\text { amplification }\end{array}$ & {$[96]$} \\
\hline $20 \mathrm{q} 13$ & & $\mathrm{CGH}$ & & $\mathrm{ADH}$-gain, $100 \%$ & Gain-100\% & Gain, $100 \%$ & {$[83]$} \\
\hline $20 \mathrm{q} 13$ region & & $\begin{array}{l}\text { Chromosomal } \\
\text { copy number }\end{array}$ & None & $\begin{array}{l}\text { ADH—amplified } \\
100 \%\end{array}$ & $\begin{array}{l}\text { Amplified- } \\
100 \%\end{array}$ & $\begin{array}{l}\text { Amplified, } \\
100 \%\end{array}$ & {$[96]$} \\
\hline $22 q$ & & $\mathrm{CGH}$ & & ADH-gain $67 \%$ & Gain- $60 \%$ & Gain, $80 \%$ & {$[83]$} \\
\hline $22 q$ & & $\begin{array}{l}\text { Chromosomal } \\
\text { imbalance/ } \\
\text { CGH }\end{array}$ & & $\mathrm{ALH}-43 \%$ & Loss, $28 \%$ & $13 \%-20 \%$ & {$[86]$} \\
\hline $22 \mathrm{q} 11.1$ & & $\mathrm{CGH}$ & & ALH-loss, $50 \%$ & & & {$[84]$} \\
\hline $\mathrm{Xp}$ & & $\mathrm{CGH}$ & & $\mathrm{ADH}-\mathrm{loss}$ & Loss & Loss & [7] \\
\hline $\mathrm{Xq}$ & & $\mathrm{CGH}$ & & $\mathrm{ADH}$-gain & Gain & Gain & [7] \\
\hline
\end{tabular}

$A I$ allelic imbalance, $L O H$ loss of heterozygosity, $C G H$ comparative genomic hybridization

For example, mutations in the tumor suppressor gene APC lead to chromosome mis-segregation as a result of kinetochore-microtubule disconnection during anaphase [27]; p53 mutations result in centrosome hyperamplification leading to multiple spindle poles and mis-segregation of chromosomes [28]; loss of p16 generates supernumerary centrosomes through centriole pair splitting, resulting in aneuploidy [29]; and BRCA1 inactivation leads to microtubule instability or centrosome amplification [30]. While speculative, one might suggest these findings indicate multiple potential pathways to the aneuploidy which is an important advanced genomic change for these lesions. Aneuploidy is also a prominent feature of high-risk normal breast tissue [31], indicating that these chromosomal changes may be a marker in general for high risk for breast cancer.

\section{Structural chromosomal changes in atypical hyperplasia}

The genomic progression from normal breast tissue to atypical hyperplasia is accompanied by the development of multiple structural chromosomal abnormalities in the form of loss of heterozygosity [(LOH)/allelic imbalance (AI)] identified by microsatellite markers, and the development of large-scale chromosomal gains and losses identified by comparative genomic hybridization (CGH). These are summarized in Table 4, and it can be seen that these alterations involve multiple chromosomes and a wide range of chromosomal loci. The LOH/AI changes in AH have been shown to involve all informative markers on a chromosome arm, consistent with the pattern found in breast cancer, and in contrast to normal breast tissue and ductal hyperplasia where AI involved only single markers [32]. Atypical hyperplasia lesions are considered to be monoclonal microsatellite alterations involving both length 


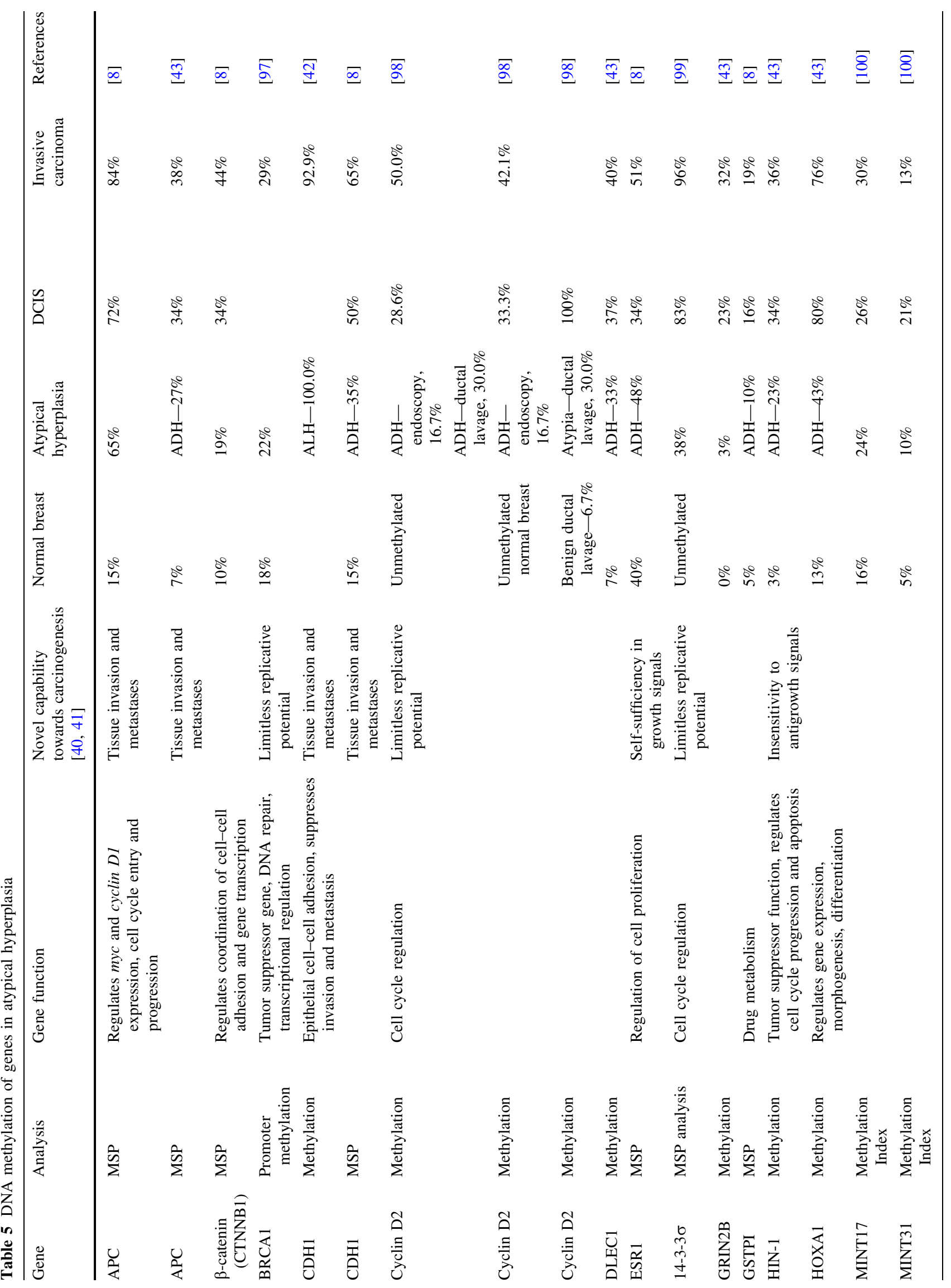




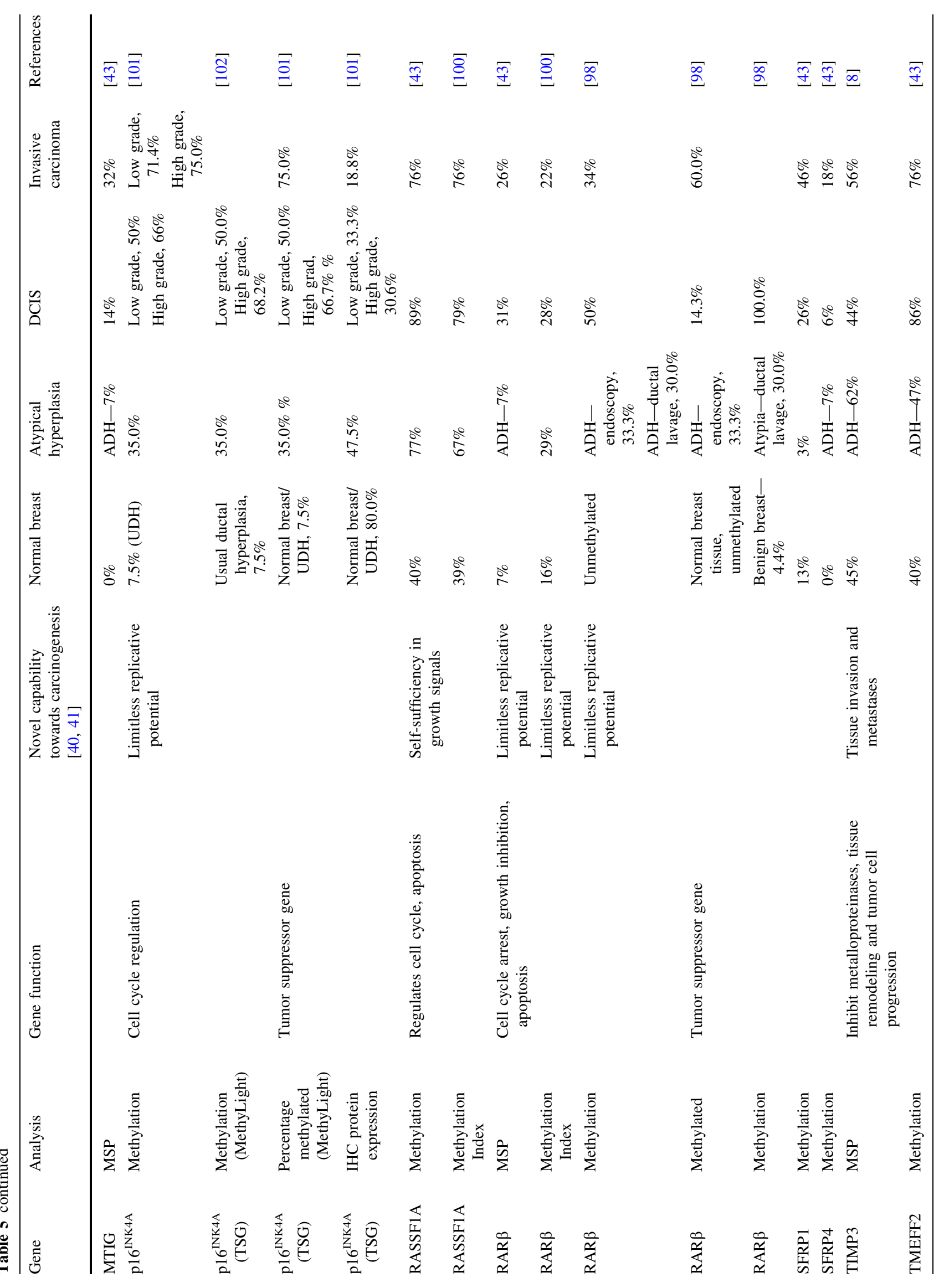




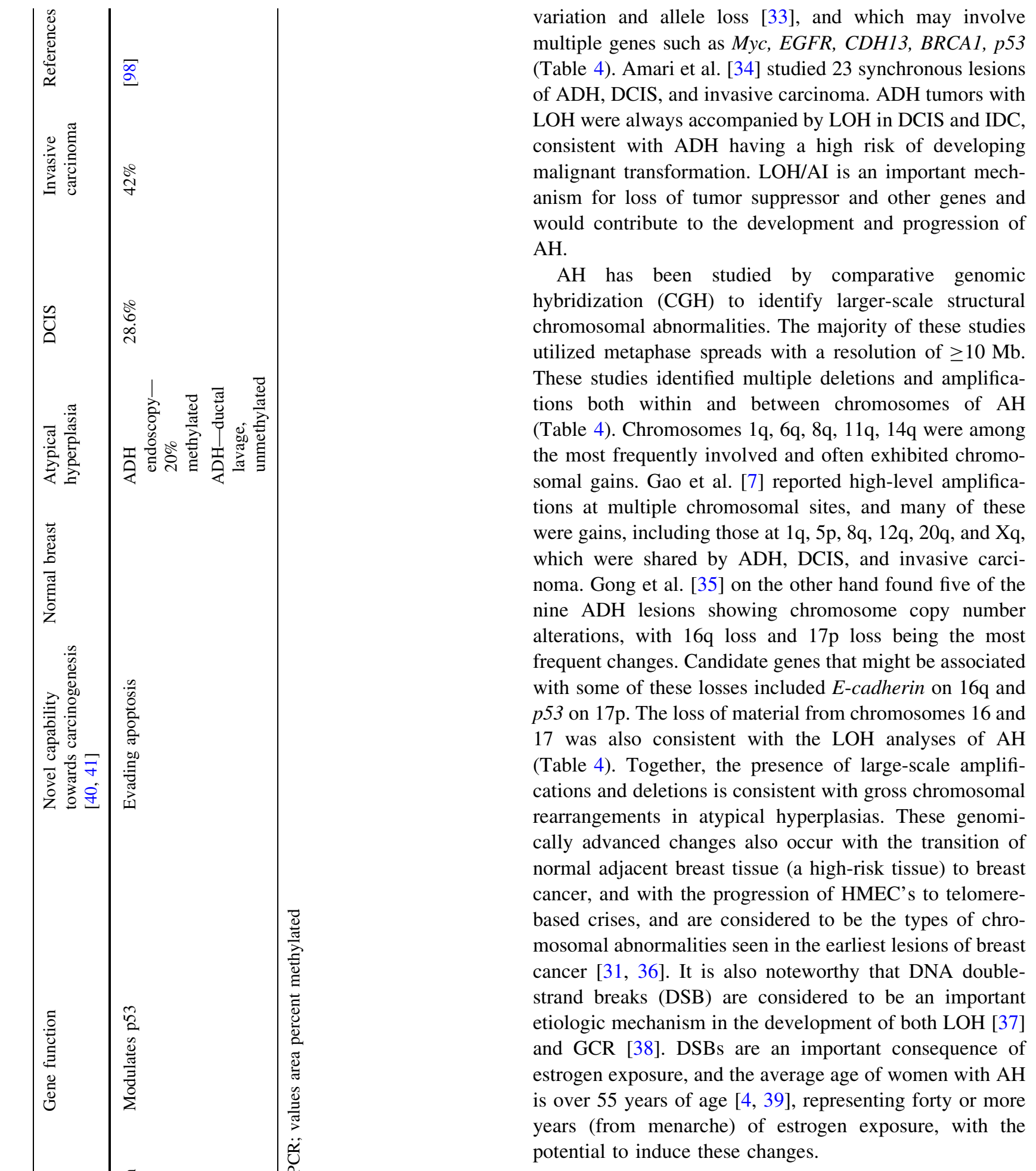

DNA methylation of genes in atypical hyperplasia

DNA methylation of $\mathrm{CpG}$ islands in the promoter region of a gene is an important mechanism for the silencing of tumor suppressor and other genes. Studies of atypical hyperplasia have identified multiple genes which may be methylated in these lesions, including tumor suppressor 
Table 6 Gene expression abnormalities in atypical hyperplasia

\begin{tabular}{|c|c|c|c|c|c|c|c|}
\hline Gene & Alteration/analysis & Function & Normal breast & $\begin{array}{l}\text { Atypical } \\
\text { hyperplasia }\end{array}$ & DCIS & $\begin{array}{l}\text { Invasive } \\
\text { carcinoma }\end{array}$ & References \\
\hline Cox-2 & $\mathrm{IHC}$ & & & $\begin{array}{l}\mathrm{ALH}-61.4 \% \\
\mathrm{ADH}-23.0 \% \\
\mathrm{ADH}+\mathrm{ALH}- \\
53.9 \%\end{array}$ & & & [103] \\
\hline Cyclin A & ISH & $\begin{array}{l}\text { Cell cycle regulation, binds } \\
\text { and activates CDK2 and } \\
\text { CDK1 kinases, and } \\
\text { promotes both cell cycle } \\
\text { G1/S and G2/M } \\
\text { transitions }\end{array}$ & $\begin{array}{l}\text { Benign breast } \\
\text { tissue- }-35.3 \%\end{array}$ & $\mathrm{ADH}-62.5 \%$ & $42.1-46.4 \%$ & $77.8 \%$ & {$[104]$} \\
\hline Cyclin D1 & $\mathrm{IHC}$ & & $\begin{array}{l}\text { Normal } \\
\text { breast- } \\
11.7 \% \\
\text { PDWA-25.0\% }\end{array}$ & $\mathrm{ADH}-39.4 \%$ & $43.6-47.9 \%$ & $48.3 \%$ & [105] \\
\hline Cyclin D1 & $\begin{array}{l}\text { Gene } \\
\text { amplification }\end{array}$ & & $\begin{array}{l}\text { Normal } \\
\text { breast }-15 \%\end{array}$ & $27 \%$ & $35 \%$ & $25 \%$ & [106] \\
\hline Cyclin D1 & IHC & & $\begin{array}{l}\text { Normal } \\
\text { breast }-13 \%\end{array}$ & $57 \%$ & $50 \%$ & $64 \%$ & [106] \\
\hline Cyclin D2 & Methylation & $\begin{array}{l}\text { A regulatory subunit of } \\
\text { CDK4 or CDK6, whose } \\
\text { activity is required for cell } \\
\text { cycle G1/S transition; } \\
\text { involved in the } \\
\text { phosphorylation of tumor } \\
\text { suppressor protein } \mathrm{Rb}\end{array}$ & $\begin{array}{l}\text { Unmethylated } \\
\text { normal breast } \\
\text { tissue }\end{array}$ & $\begin{array}{l}\text { ADH- } \\
\text { endoscopy, } \\
16.7 \% \\
\text { methylated }\end{array}$ & $33.3 \%$ & $42.1 \%$ & [98] \\
\hline Cyclin D2 & Methylation & & $\begin{array}{l}\text { Benign ductal } \\
\text { lavage- }-6.7 \%\end{array}$ & $\begin{array}{l}\text { Atypia-ductal } \\
\text { lavage, } 30.0 \% \\
\text { methylated }\end{array}$ & $100.0 \%$ & & {$[98]$} \\
\hline $\begin{array}{l}\text { EGFR } \\
(\text { HER-1) }\end{array}$ & IHC & $\begin{array}{l}\text { Regulate cell growth, } \\
\text { differentiation, and } \\
\text { survival }\end{array}$ & $\begin{array}{l}\text { Non- } \\
\text { proliferative- } \\
21 \%\end{array}$ & $\begin{array}{l}\text { Epithelial } \\
\text { hyperplasia } \\
\text { with atypia- } \\
60 \%\end{array}$ & & & [79] \\
\hline $\mathrm{EZH} 2$ & IHC & Transcriptional repression & $\begin{array}{l}\text { Normal } \\
\text { breast- }-0.0 \%\end{array}$ & $\begin{array}{l}\text { ADH without } \\
\text { DCIS-10\% } \\
\text { ADH with } \\
\text { DCIS-40.0\% }\end{array}$ & $45 \%$ & & {$[52]$} \\
\hline FHIT & IHC/H-score & $\begin{array}{l}\text { Controls proliferation and } \\
\text { apoptosis }\end{array}$ & $\begin{array}{l}\text { Normal adjacent } \\
\text { to cancer, } \\
\text { strong and } \\
\text { uniform, } \\
100 \% ; 2.95 / \\
3.0\end{array}$ & $\begin{array}{l}\text { Loss of FHIT } \\
\text { protein vs } \\
\text { normal }\end{array}$ & $\begin{array}{l}\text { Marked } \\
\text { loss of } \\
\text { FHIT } \\
\text { protein, } \\
75 \%\end{array}$ & $\begin{array}{l}\text { Marked } \\
\text { loss of } \\
\text { FHIT } \\
\text { protein, } \\
54 \% \text {; } \\
0-1.0 / 3.0\end{array}$ & {$[107]$} \\
\hline FHIT & mRNA & & $\begin{array}{c}\text { Normal adjacent } \\
\text { to } \mathrm{ADH}, 86 \%\end{array}$ & $71 \%$ & $45 \%$ & $29 \%$ & {$[108]$} \\
\hline FHIT & Western blot & & $\begin{array}{l}82 \% \\
\text { Normal adjacent } \\
\text { to } \mathrm{AH}\end{array}$ & $57 \%$ & $45 \%$ & $27 \%$ & {$[108]$} \\
\hline HER-2/neu & $\begin{array}{l}\text { Amplification } \\
\text { FISH }\end{array}$ & & $\begin{array}{l}\text { Normal adjacent } \\
\text { to } \mathrm{ADH} \text {, no } \\
\text { amplification }\end{array}$ & $\begin{array}{l}\mathrm{ADH}-53.8 \% \\
\text { amplified }\end{array}$ & $\begin{array}{l}95.5 \% \\
\text { amplified }\end{array}$ & $\begin{array}{l}100 \% \\
\text { amplified }\end{array}$ & [109] \\
\hline $\begin{array}{l}\text { HER-2/neu } \\
\text { (C-erbB- } \\
\text { 2) }\end{array}$ & $\mathrm{IHC}$ & & $\begin{array}{l}\text { Non- } \\
\text { proliferative- } \\
15 \%\end{array}$ & $\begin{array}{l}\text { Epithelial } \\
\text { hyperplasia } \\
\text { with atypia- } \\
40 \%\end{array}$ & & & [79] \\
\hline
\end{tabular}


Table 6 continued

\begin{tabular}{|c|c|c|c|c|c|c|c|}
\hline Gene & Alteration/analysis & Function & Normal breast & $\begin{array}{l}\text { Atypical } \\
\text { hyperplasia }\end{array}$ & DCIS & $\begin{array}{l}\text { Invasive } \\
\text { carcinoma }\end{array}$ & References \\
\hline $\begin{array}{l}\text { HER-2/neu } \\
\text { (C-erbB- } \\
\text { 2) }\end{array}$ & IHC & & $\begin{array}{l}\text { Ductal } \\
\text { hyperplasia } \\
\text { without } \\
\text { atypia- } \\
13.3 \%\end{array}$ & $\begin{array}{l}\text { Atypia (mild- } \\
\text { severe) } \\
30-56.6 \%\end{array}$ & $31.9 \%$ & $17.8 \%$ & [110] \\
\hline Myc & IHC & & $\begin{array}{l}\text { Benign lesions, } \\
31 \%\end{array}$ & $66.7 \%$ & $45 \%$ & $66.7 \%$ & {$[111]$} \\
\hline P53 & $\begin{array}{l}\text { Sequencing, } \\
\text { mutations }\end{array}$ & & & $\begin{array}{l}\mathrm{ADH}-28.6 \% \\
\text { insertion, } \\
\text { deletion }\end{array}$ & & $34.1 \%$ & {$[45]$} \\
\hline P53 & Mutation-gel elect & & & $\mathrm{ADH}-1$ case & $31.5 \%$ & $55.7 \%$ & [47] \\
\hline P53 & $\begin{array}{l}\text { SSCP, } \\
\text { sequencing; } \\
\text { mutation }\end{array}$ & & $\begin{array}{l}\text { Normal adjacent } \\
\text { to cancer, no } \\
\text { mutations }\end{array}$ & $\begin{array}{l}\mathrm{ADH}-50 \% \\
\text { (not adjacent } \\
\text { to cancer) }\end{array}$ & $50 \%$ & & [46] \\
\hline $\mathrm{RB}$ & IHC & & $\begin{array}{l}\text { Normal breast, } \\
\text { weak staining }\end{array}$ & $\begin{array}{l}\mathrm{ADH}, \mathrm{mod} / \\
\text { strong- } 11 \%\end{array}$ & $\begin{array}{l}\text { Mod/ } \\
\text { strong- } \\
64 \%\end{array}$ & $\begin{array}{l}\text { Mod/ } \\
\text { strong- } \\
47 \%\end{array}$ & [112] \\
\hline Stat3 & IHC & $\begin{array}{l}\text { Regulates genes that are } \\
\text { involved in cell growth } \\
\text { and division, cell } \\
\text { movement, and apoptosis }\end{array}$ & $\begin{array}{l}\text { Normal breast, } \\
12.8 \%\end{array}$ & $\begin{array}{l}\mathrm{ADH}, 30.0 \% \\
\mathrm{ADH} \text { adjacent } \\
\text { to breast } \\
\text { cancer, } \\
31.15 \%\end{array}$ & & & [113] \\
\hline Stat5 & $\mathrm{IHC}$ & & $\begin{array}{l}\text { Normal breast, } \\
17.1 \%\end{array}$ & $\mathrm{ADH}-31.65 \%$ & & & [113] \\
\hline $\begin{array}{l}\text { Telomere, } \\
\text { anaphase } \\
\text { bridges }\end{array}$ & FISH & & & $\mathrm{ADH}-16.7 \%$ & $18.2 \%$ & & [114] \\
\hline $\begin{array}{l}\text { Telomerase } \\
\text { activity }\end{array}$ & TRAP signal & & $\begin{array}{l}\text { Benign breast } \\
\text { disease, } 14.0 \%\end{array}$ & $\begin{array}{l}\text { Atypical } \\
\text { hyperplasia, } \\
100 \%, \text { focal } \\
\text { high } \\
\text { expression }\end{array}$ & $92 \%$ strong & $\begin{array}{l}94 \% \\
\text { strong }\end{array}$ & {$[115]$} \\
\hline Telomerase & $\begin{array}{l}\text { Human telomerase } \\
\text { gene (hTR) }\end{array}$ & & $\begin{array}{l}\text { Simple } \\
\text { hyperplasia, } \\
16.6 \%\end{array}$ & $\begin{array}{l}\text { ADH mild- } \\
22 \% \\
\text { ADH } \\
\text { moderate- } \\
33.3 \% \\
\text { ADH severe- } \\
60.9 \%\end{array}$ & $85.7 \%$ & $91.7 \%$ & [116] \\
\hline Telomerase & $\begin{array}{l}\text { Human reverse } \\
\text { transcriptase } \\
\text { gene (hTRT) }\end{array}$ & & $\begin{array}{l}\text { Simple } \\
\text { hyperplasia, } \\
0.0 \%\end{array}$ & $\begin{array}{l}\text { ADH mild- } \\
11.1 \% \\
\text { ADH } \\
\text { moderate- } \\
25.0 \% \\
\text { ADH severe- } \\
52.1 \%\end{array}$ & $78.6 \%$ & $83.3 \%$ & [116] \\
\hline$\alpha$-tubulin & $\begin{array}{l}\text { mRNA } \\
\text { expression- } \\
\text { percent positive }\end{array}$ & $\begin{array}{l}\text { Structural components of } \\
\text { centrosomes }\end{array}$ & $\begin{array}{l}\text { Normal breast, } \\
33.3 \%\end{array}$ & $\mathrm{ADH}-62.5 \%$ & $82.5 \%$ & $77.5 \%$ & [49] \\
\hline$\alpha$-tubulin & Protein expression & & $\begin{array}{l}\text { Normal breast, } \\
31.7 \%\end{array}$ & $\mathrm{ADH}-65 \%$ & $86.3 \%$ & $87.5 \%$ & [49] \\
\hline
\end{tabular}


Table 6 continued

\begin{tabular}{|c|c|c|c|c|c|c|}
\hline Gene & Alteration/analysis Function & Normal breast & $\begin{array}{l}\text { Atypical } \\
\text { hyperplasia }\end{array}$ & DCIS & $\begin{array}{l}\text { Invasive } \\
\text { carcinoma }\end{array}$ & References \\
\hline \multirow[t]{2}{*}{$\alpha$-tubulin } & $\begin{array}{l}\text { DNA copy } \\
\text { number }\end{array}$ & $\begin{array}{l}\text { Normal breast, } \\
2.05\end{array}$ & $\mathrm{ADH}-4.31$ & 5.54 & 5.15 & [49] \\
\hline & $\begin{array}{l}\text { Centrosome } \\
\text { abnormality- } \\
\text { frequency }\end{array}$ & $\begin{array}{l}\text { Normal breast, } \\
0 \%\end{array}$ & $\mathrm{ADH}-30 \%$ & $52.5 \%$ & $70.0 \%$ & [49] \\
\hline$\gamma$-tubulin & $\begin{array}{l}\text { mRNA } \\
\text { expression- } \\
\text { percent positive }\end{array}$ & $\begin{array}{l}\text { Normal breast, } \\
30.0 \%\end{array}$ & ADH $57.5 \%$ & $85.0 \%$ & $82.5 \%$ & [49] \\
\hline$\gamma$-tubulin & Protein expression & $\begin{array}{l}\text { Normal breast } \\
35.0 \%\end{array}$ & $\mathrm{ADH}-58.8 \%$ & $86.3 \%$ & $85.0 \%$ & [49] \\
\hline Ki67 & $\mathrm{IHC}$ & $\begin{array}{l}\text { Normal breast, } \\
1.5 \% \\
\text { PBBD without } \\
\text { atypia, } 3.5 \%\end{array}$ & $\begin{array}{l}\text { PBBD with } \\
\text { atypia, } 16 \%\end{array}$ & $\begin{array}{l}\text { Non-high- } \\
\text { grade, } \\
6.1 \% \\
\text { High grade, } \\
17.3 \%\end{array}$ & & {$[54]$} \\
\hline Ki67 & $\mathrm{IHC}$ & $\begin{array}{l}\text { Normal breast, } \\
0.1 \% \\
\text { Usual } \\
\text { hyperplasia, } \\
3.3 \%\end{array}$ & $\mathrm{ADH}-8.2 \%$ & $8.7 \%$ & $21.1 \%$ & [117] \\
\hline
\end{tabular}

PDWA proliferative benign breast disease without atypia, $I H C$ immunohistochemistry, $I S H$ In situ hybridization, $P B B D$ Proliferative benign breast disease

genes known to be important in breast carcinogenesis

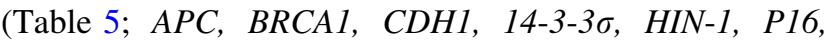
$R A S S F 1 A, R A R \beta)$. A number of cellular processes may be altered by inactivation of these genes, including cell cycle control, DNA repair, cell-cell adhesion, cell proliferation, apoptosis, cellular differentiation, and centrosome and mitotic events. Importantly, methylation in $\mathrm{AH}$ involves genes which are also instrumental in five of the six capabilities a cell has to acquire to become malignant (tissue invasion and metastases, limitless replicative potential, self-sufficiency in growth signals, insensitivity to antigrowth signals, and evading apoptosis) [40, 41], supporting an early and important role in breast carcinogenesis. A review of Table 5 indicates there is clearly heterogeneity in the incidence of methylation in these lesions, and in some cases methylation may also be monoallelic ( $C D H 1)$ [42], further contributing to a range of gene inactivation. DNA methylation of tumor suppressor and other genes appears to play an important role in the progression of $\mathrm{AH}$ to breast cancer. Park et al. [43] examined methylation patterns in synchronous ADH, DCIS, and invasive ductal carcinoma. They found overall methylation levels and frequencies of $A P C, D L E C 1, H O X A 1$, and RASSF1A promoter CpG islands were significantly higher in ADH than in normal breast tissue, while GRIN2B, GSTP1, HOXA1, RAR $\beta$, $R U N X 3, S F R P 1$, and TMEFF2 showed higher methylation levels and frequencies in DCIS than in ADH. This indicated that promoter methylation changed significantly in pre-invasive lesions and suggested that $\mathrm{CpG}$ island methylation of tumor-related genes is an early event in breast cancer progression. Hoque et al. [8] studied synchronous ADH, DCIS, and invasive ductal carcinoma. For the genes $A P C, C D H 1$, and $C T N N B 1$ they found methylation at two or three gene loci in $25 \%$ of $\mathrm{ADH}, 28 \%$ of DCIS, and $37 \%$ in IDC. They noted atypical ductal hyperplasia and in situ carcinoma showed similar methylation patterns, suggesting that atypical hyperplasia should be considered as a well-differentiated or simply small in situ carcinoma. DNA methylation may also contribute to chromosomal abnormalities in AH. It was seen above that $A P C$ and $p 16 I N K 4 a$ regulate centrosome duplication and chromosome segregation, and loss of these genes through DNA methylation would be expected to contribute to chromosomal instability and aneuploidy [27, 29]. Together these findings indicate that DNA methylation is not only involved in the formation of $\mathrm{AH}$ and contributes significantly to its genomic instability, but also plays an important role in subsequent progression to malignancy.

\section{Gene expression abnormalities}

The development of ADH and progression to DCIS and invasive breast cancer is accompanied by the acquisition of multiple gene expression differences. This is demonstrated both by gene expression profiling studies and by multiple individual gene expression studies. Ma et al. [9] examined 
gene expression profiling in specimens containing invasive ductal carcinoma (IDC)/DCIS/ADH/adjacent normal tissue. They found that, as compared with the patient-matched adjacent normal epithelium, significant global alterations in gene expression occurred in $\mathrm{ADH}$, and these alterations were maintained in the later stages of DCIS and IDC. All of the ADH samples demonstrated a grade I gene expression signature and clustered with the low-grade DCIS and IDC samples. These three distinct stages of breast cancer (ADH, DCIS, IDC) were thus highly similar to each other at the level of the transcriptome, supporting the idea that the distinct stages of progression are evolutionary products of the same clonal origin [9].

Studies of individual genes in atypical hyperplasia indicate altered expression in multiple genes effecting a wide range of signaling pathways and cellular functions (Table 6), further supporting the gene expression profiling differences between $\mathrm{ADH}$ and normal adjacent tissue described above. These genes include estrogen receptor and estrogen-related genes $(E R, E Z H 2)$, cell cycle genes (cyclin A1, D1, D2), loss of tumor suppressor genes (FHIT, $p 16, p 53, R A R \beta)$ increased mitogenic activity of growth factors and oncogenes (EGFR, Her-2/neu, myc), and increased expression of transcription factors (STAT 3,5). Together these alterations may contribute to increased estrogen responsiveness, increased cell cycle progression, development of aneuploidy, decreased apoptosis, and loss of cell-cell adhesion. Alterations in many of these genes may also be associated with increased proliferation which is confirmed by increased expression of Ki67 (Table 6), a measure of cellular proliferation. Interestingly, Ki67 has also been found to be a time-varying biomarker of risk of breast cancer in women with atypical hyperplasia [44]. There is evidence that $p 53$ is mutated in ADH [45-47]. The presence of a dysfunctional p53 could have widespread effects in these cells including loss of cell cycle arrest and apoptosis, altered DNA repair, and genomic instability [48]. Alterations in $\boldsymbol{\alpha}$-tubulin and $\gamma$-tubulin are also observed in $\mathrm{AH}$ [49], further disrupting chromosome segregation and contributing to the aneuploidy which is observed in atypical hyperplasia (see above, numerical chromosomal changes). Importantly, it can be seen in Table 6 that for virtually all of these genes (a) the expression in ADH is altered compared with that of normal and/or non-proliferative breast tissue, and (b) this expression difference is maintained or increased in DCIS and invasive breast cancer. This is further evidence that multiple genes regulating multiple cellular processes contribute to formation of $\mathrm{ADH}$ and its genomic instability and are instrumental in the progression of $\mathrm{ADH}$ to DCIS and invasive breast cancer.

\section{Estrogen receptor in atypical hyperplasia}

The expression of $\mathrm{ER} \alpha$ in atypical hyperplasia is high $[12,50]$, and in some series all of the ADH lesion expressed ER [12, 51], consistent with both a prominent sensitivity to estrogens and a clonally expanded population of cells. Estradiol is an important mitogen, and the increased ER content promotes proliferation and clonal expansion, while at the same time increasing the accumulation of mutational changes. The gene EZH2 is also increased in AH and DCIS [52], and this gene transactivates genes that are commonly targeted by estrogen and WNT signaling pathways and promotes cell cycle progression in breast cancer cells [53]. The functional ER and its role in proliferation also makes it an excellent potential target for antiestrogen prevention therapy. Efficacy of tamoxifen in the prevention of breast cancer in women with AH was demonstrated in the NSABP-P1 trial [13]. Closely related to this point, the finding that antiestrogen therapy reduces breast cancer development in the ipsilateral and contralateral breast indicates that this characteristic of $\mathrm{AH}$ (ER positivity) is reflected in the genomic characteristics of the remaining normal breast tissue. If other genomic characteristics of $\mathrm{AH}$ are also reflected in these normal tissues, then the molecular profile of $\mathrm{AH}$ could be important for assessing future risk and responsiveness of these normal tissues. Lastly, the expression of $E R \beta$ is decreased in atypical hyperplasia [54]. $E R \beta$ is considered to play an oncosuppressive role in breast cancer [55]. Low ER $\beta 2$ expression, combined with increased ER $\alpha$ expression could further promote progression along the AH-DCIS/invasive carcinoma pathway.

\section{Metachronous breast cancer associated with atypical hyperplasia}

Women with $\mathrm{AH}$ are at significant risk for the development of metachronous breast cancer (MBC), and it is noteworthy that the characteristics of this event for $\mathrm{AH}$ are very similar to those of women with sporadic breast cancer for the development of contralateral breast cancer (CBC): (a) $\mathrm{AH}$ contains multiple advanced genomic changes including aneuploidy, gross chromosomal rearrangements, and DNA methylation of tumor suppressor genes, all of which are common in sporadic breast cancer. (b) Both MBC and CBC are more commonly invasive breast cancer, less commonly DCIS (Table 2) [56]. (c) The cumulative incidence of breast cancer appears to increase linearly over time in both MBC [5] and CBC [56, 57]. (d) The annual incidence of breast cancer development of MBC (estimated to be approx. 0.9\%/year from Hartmann [5], Fig. 2) is very similar to $0.6-0.7 \%$ year for $\mathrm{CBC}[56,58]$. (e) The incidence of both $\mathrm{MBC}$ and $\mathrm{CBC}$ are reduced by antiestrogens 


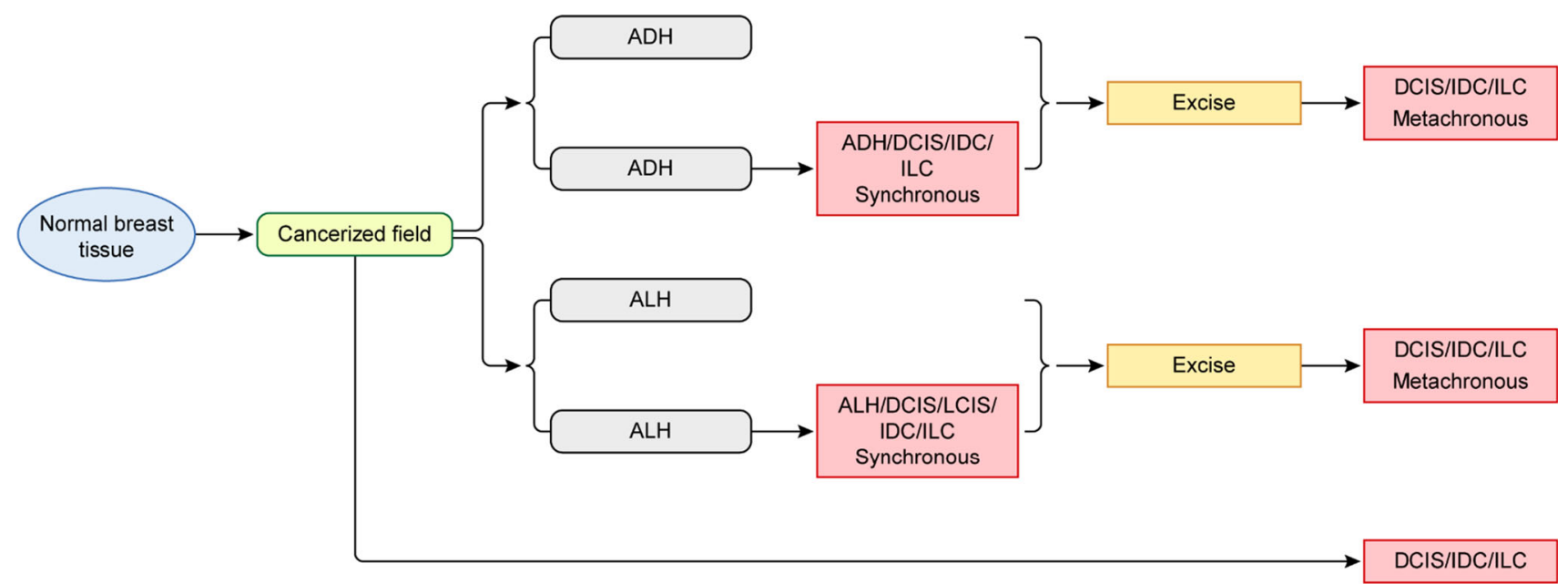

Fig. 1 Development and progression of atypical hyperplasia to breast cancer. Atypical hyperplasia (ALH or ADH) develops within a cancerized field in normal breast tissue (Fig. 1) [31, 118]. AH may present as a solitary lesion (single or multifocal). Local progression of $\mathrm{AH}$ results in the development of DCIS/IDC which appear

$[13,59]$. Together, these findings indicate that many of the features of carcinogenesis of $\mathrm{AH}$ are shared by sporadic breast cancer, and have strong carcinogenic potential for the future development of metachronous breast cancer.

\section{Summary and conclusions}

Atypical ductal and atypical lobular hyperplasia possess a wide range of advanced genomic changes including aneuploidy, loss of heterozygosity, gross chromosomal rearrangement such as amplifications and large-scale deletions, DNA methylation of tumor suppressor and other genes, and gene expression differences which are associated with a significant risk for breast cancer. These genomic changes progress from associated normal breast tissue, indicating an important role in the development of ADH. Many of these genomic charges are also shared by synchronously associated DCIS and invasive carcinoma, suggesting they are an important part of the progression of atypical hyperplasia to breast cancer. At the same time many of these changes, including ER expression, are also shared by standard sporadic breast cancer and thus reflect the propensity of distant normal breast tissue to develop metachronous or contralateral breast cancer. These developmental patterns and relationship of $\mathrm{AH}$ to breast cancer are summarized in Fig. 1. Knowledge of a comprehensive profile of the genomic changes of $\mathrm{AH}$ should increase our understanding of high-risk lesions of the breast, promote identification of new targets for breast cancer prevention, and clarify progression in the carcinogenic pathway. synchronously with the AH. Excision of the primary AH (solitary or with synchronous carcinoma) may then be followed by the development of metachronous breast cancer-DCIS/IDC/ILC. Included in Fig. 1 is a separate pathway in which breast cancer develops without any intervening atypical lesion

Funding This research was supported by the Intramural Research Program, National Cancer Institute, Center for Cancer Research, National Institutes of Health, Bethesda, MD.

\section{Compliance with ethical standards}

Conflict of interest The author is employed by the National Institutes of Health which funded this manuscript. The author has no conflicts of interest with the NIH.

Open Access This article is distributed under the terms of the Creative Commons Attribution 4.0 International License (http://crea tivecommons.org/licenses/by/4.0/), which permits unrestricted use, distribution, and reproduction in any medium, provided you give appropriate credit to the original author(s) and the source, provide a link to the Creative Commons license, and indicate if changes were made.

\section{References}

1. Page DL, Dupont WD, Rogers LW, Rados MS (1985) Atypical hyperplastic lesions of the female breast. A long-term follow-up study. Cancer 55(11):2698-2708

2. Page DL, Schuyler PA, Dupont WD, Jensen RA, Plummer WD Jr, Simpson JF (2003) Atypical lobular hyperplasia as a unilateral predictor of breast cancer risk: a retrospective cohort study. Lancet 361(9352):125-129

3. Roy D, Liehr JG (1999) Estrogen. DNA damage and mutations. Mutat Res 424(1-2):107-115

4. Degnim AC, Visscher DW, Berman HK, Frost MH, Sellers TA, Vierkant RA, Maloney SD, Pankratz VS, de Groen PC, Lingle WL, Ghosh K, Penheiter L, Tlsty T, Melton LJ III, Reynolds CA, Hartmann LC (2007) Stratification of breast cancer risk in women with atypia: a Mayo cohort study. J Clin Oncol 25(19):2671-2677

5. Hartmann LC, Degnim AC, Santen RJ, Dupont WD, Ghosh K (2015) Atypical hyperplasia of the breast-risk assessment and management options. N Engl J Med 372(1):78-89 
6. Crissman JD, Visscher DW, Kubus J (1990) Image cytophotometric DNA analysis of atypical hyperplasias and intraductal carcinomas of the breast. Arch Pathol Lab Med 114(12):1249-1253

7. Gao Y, Niu Y, Wang X, Wei L, Lu S (2009) Genetic changes at specific stages of breast cancer progression detected by comparative genomic hybridization. J Mol Med 87(2):145-152

8. Hoque MO, Prencipe M, Poeta ML, Barbano R, Valori VM, Copetti M, Gallo AP, Brait M, Maiello E, Apicella A, Rossiello R, Zito F, Stefania T, Paradiso A, Carella M, Dallapiccola B, Murgo R, Carosi I, Bisceglia M, Fazio VM, Sidransky D, Parrella $P$ (2009) Changes in $\mathrm{CpG}$ islands promoter methylation patterns during ductal breast carcinoma progression. Cancer Epidemiol Biomarkers Prev 18(10):2694-2700

9. Ma XJ, Salunga R, Tuggle JT, Gaudet J, Enright E, McQuary P, Payette T, Pistone M, Stecker K, Zhang BM, Zhou YX, Varnholt H, Smith B, Gadd M, Chatfield E, Kessler J, Baer TM, Erlander MG, Sgroi DC (2003) Gene expression profiles of human breast cancer progression. Proc Natl Acad Sci USA 100(10):5974-5979

10. Murray MP, Luedtke C, Liberman L, Nehhozina T, Akram M, Brogi E (2013) Classic lobular carcinoma in situ and atypical lobular hyperplasia at percutaneous breast core biopsy: outcomes of prospective excision. Cancer 119(5):1073-1079. doi:10.1002/cncr.27841

11. Shah-Khan MG, Geiger XJ, Reynolds C, Jakub JW, Deperi ER, Glazebrook KN (2012) Long-term follow-up of lobular neoplasia (atypical lobular hyperplasia/lobular carcinoma in situ) diagnosed on core needle biopsy. Ann Surg Oncol 19(10):3131-3138. doi:10.1245/s10434-012-2534-9

12. Shoker BS, Jarvis C, Sibson DR, Walker C, Sloane JP (1999) Oestrogen receptor expression in the normal and pre-cancerous breast. J Pathol 188(3):237-244

13. Fisher B, Costantino JP, Wickerham DL, Cecchini RS, Cronin WM, Robidoux A, Bevers TB, Kavanah MT, Atkins JN, Margolese RG, Runowicz CD, James JM, Ford LG, Wolmark N (2005) Tamoxifen for the prevention of breast cancer: current status of the National Surgical Adjuvant Breast and Bowel Project P-1 study. J Natl Cancer Inst 97(22):1652-1662. doi:10. 1093/jnci/dji372

14. Page DL, Dupont WD, Rogers LW (1988) Ductal involvement by cells of atypical lobular hyperplasia in the breast: a long-term follow-up study of cancer risk. Hum Pathol 19(2):201-207

15. Schnitt SJ, Connolly JL, Tavassoli FA, Fechner RE, Kempson RL, Gelman R, Page DL (1992) Interobserver reproducibility in the diagnosis of ductal proliferative breast lesions using standardized criteria. Am J Surg Pathol 16(12):1133-1143

16. Sneige N, Sahin A, Dinh M, El Naggar A (1996) Interphase cytogenetics in mammographically detected breast lesions. Hum Pathol 27(4):330-335

17. Mariuzzi L, Mombello A, Granchelli G, Rucco V, Tarocco E, Frank D, Davis J, Thompson D, Bartels H, Mariuzzi GM, Bartels PH (2002) Quantitative study of breast cancer progression: different pathways for various in situ cancers. Mod Pathol 15(1):18-25

18. Di Stefano D, Scucchi L, Limiti MR, Mingazzini PL, Marinozzi V (1996) Modifications of interphasic NORs as a diagnostic parameter of atypical lesions of the female breast. Anticancer Res 16(4A): 1953-1961

19. Schmitt FC, Leal C, Lopes C (1995) p53 protein expression and nuclear DNA content in breast intraductal proliferations. J Pathol 176(3):233-241

20. Micale MA, Visscher DW, Gulino SE, Wolman SR (1994) Chromosomal aneuploidy in proliferative breast disease. Hum Pathol 25(1):29-35
21. Yu Q, Niu Y, Yu Y, Ding X, Shi Y (2009) Analysis of the progression of intraductal proliferative lesions in the breast by PCR-based clonal assay. Breast Cancer Res Treat 114(3):433-440

22. Eriksson E, Schimmelpenning H, Silfversward C, Auer G (1992) Immunoreactivity with monoclonal antibody A-80 and nuclear DNA content in benign and malignant human breast disease. Hum Pathol 23:1366-1372

23. Cummings MC, Aubele M, Mattis A, Purdie D, Hutzler P, Hofler H, Werner M (2000) Increasing chromosome 1 copy number parallels histological progression in breast carcinogenesis. Br J Cancer 82(6):1204-1210

24. Rajagopalan H, Lengauer C (2004) Aneuploidy and cancer. Nature 432(7015):338-341

25. Ried T, Hu Y, Difilippantonio MJ, Ghadimi BM, Grade M, Camps J (2012) The consequences of chromosomal aneuploidy on the transcriptome of cancer cells. Biochim Biophys Acta 1819(7):784-793

26. Pfau SJ, Amon A (2012) Chromosomal instability and aneuploidy in cancer: from yeast to man. EMBO Rep 13(6):515-527

27. Fodde R, Kuipers J, Rosenberg C, Smits R, Kielman M, Gaspar C, van Es JH, Breukel C, Wiegant J, Giles RH, Clevers H (2001) Mutations in the APC tumour suppressor gene cause chromosomal instability. Nat Cell Biol 3(4):433-438. doi:10.1038/ 35070129

28. Liu G, Parant JM, Lang G, Chau P, Chavez-Reyes A, El-Naggar AK, Multani A, Chang S, Lozano G (2004) Chromosome stability, in the absence of apoptosis, is critical for suppression of tumorigenesis in Trp53 mutant mice. Nat Genet 36(1):63-68

29. McDermott KM, Zhang J, Holst CR, Kozakiewicz BK, Singla V, Tlsty TD (2006) p16(INK4a) prevents centrosome dysfunction and genomic instability in primary cells. PLoS Biol 4(3):e51

30. Kops GJ, Weaver BA, Cleveland DW (2005) On the road to cancer: aneuploidy and the mitotic checkpoint. Nat Rev Cancer 5(10):773-785

31. Danforth DN Jr (2016) Genomic changes in normal breast tissue in women at normal risk or at high risk for breast cancer. Breast Cancer 10:109-146. doi:10.4137/bcbcr.s39384

32. Larson PS, de las MA, Cerda SR, Bennett SR, Cupples LA, Rosenberg CL (2006) Quantitative analysis of allele imbalance supports atypical ductal hyperplasia lesions as direct breast cancer precursors. J Pathol 209(3):307-316

33. Rosenberg CL, de las MA, Huang K, Cupples LA, Faller DV, Larson PS (1996) Detection of monoclonal microsatellite alterations in atypical breast hyperplasia. J Clin Invest 98(5):1095-1100

34. Amari M, Suzuki A, Moriya T, Yoshinaga K, Amano G, Sasano H, Ohuchi N, Satomi S, Horii A (1999) LOH analyses of premalignant and malignant lesions of human breast: frequent $\mathrm{LOH}$ in $8 \mathrm{p}, 16 \mathrm{q}$, and $17 \mathrm{q}$ in atypical ductal hyperplasia. Oncol Rep 6(6): $1277-1280$

35. Gong G, DeVries S, Chew KL, Cha I, Ljung BM, Waldman FM (2001) Genetic changes in paired atypical and usual ductal hyperplasia of the breast by comparative genomic hybridization. Clin Cancer Res 7(8):2410-2414

36. Romanov SR, Kozakiewicz BK, Holst CR, Stampfer MR, Haupt LM, Tlsty TD (2001) Normal human mammary epithelial cells spontaneously escape senescence and acquire genomic changes. Nature 409(6820):633-637

37. Thiagalingam S, Laken S, Willson JK, Markowitz SD, Kinzler KW, Vogelstein B, Lengauer C (2001) Mechanisms underlying losses of heterozygosity in human colorectal cancers. Proc Natl Acad Sci USA 98(5):2698-2702

38. Kurahashi H, Bolor H, Kato T, Kogo H, Tsutsumi M, Inagaki H, Ohye T (2009) Recent advance in our understanding of the 
molecular nature of chromosomal abnormalities. J Hum Genet 54(5):253-260. doi:10.1038/jhg.2009.35

39. Hartmann LC, Schaid DJ, Woods JE, Crotty TP, Myers JL, Arnold PG, Petty PM, Sellers TA, Johnson JL, McDonnell SK, Frost MH, Jenkins RB (1999) Efficacy of bilateral prophylactic mastectomy in women with a family history of breast cancer. N Engl J Med 340(2):77-84

40. Hanahan D, Weinberg RA (2000) The hallmarks of cancer. Cell 100(1):57-70

41. Widschwendter M, Jones PA (2002) DNA methylation and breast carcinogenesis. Oncogene 21(35):5462-5482

42. Zou D, Yoon HS, Perez D, Weeks RJ, Guilford P, Humar B (2009) Epigenetic silencing in non-neoplastic epithelia identifies E-cadherin (CDH1) as a target for chemoprevention of lobular neoplasia. J Pathol 218:265-272

43. Park SY, Kwon HJ, Lee HE, Ryu HS, Kim SW, Kim JH, Kim IA, Jung N, Cho NY, Kang GH (2011) Promoter CpG island hypermethylation during breast cancer progression. Virchows Arch 458(1):73-84

44. Santisteban M, Reynolds C, Barr Fritcher EG, Frost MH, Vierkant RA, Anderson SS, Degnim AC, Visscher DW, Pankratz VS, Hartmann LC (2010) Ki67: a time-varying biomarker of risk of breast cancer in atypical hyperplasia. Breast Cancer Res Treat 121(2):431-437

45. Kang JH, Kim SJ, Noh DY, Choe KJ, Lee ES, Kang HS (2001) The timing and characterization of p53 mutations in progression from atypical ductal hyperplasia to invasive lesions in the breast cancer. J Mol Med (Berlin, Germany) 79(11):648-655. doi:10. 1007/s001090100269

46. Keohavong P, Gao WM, Mady HH, Kanbour-Shakir A, Melhem MF (2004) Analysis of p53 mutations in cells taken from paraffin-embedded tissue sections of ductal carcinoma in situ and atypical ductal hyperplasia of the breast. Cancer Lett 212(1):121-130

47. Lisboa BW, Vogtlander S, Gilster T, Riethdorf L, Milde-Langosch K, Loning T (1997) Molecular and immunohistochemical analysis of p53 mutations in scrapings and tissue from preinvasive and invasive breast cancer. Virchows Arch 431(6):375-381

48. Vousden KH, Lane DP (2007) p53 in health and disease. Nat Rev Mol Cell Biol 8(4):275-283

49. Niu Y, Liu T, Tse GM, Sun B, Niu R, Li HM, Wang H, Yang Y, Ye X, Wang Y, Yu Q, Zhang F (2009) Increased expression of centrosomal alpha, gamma-tubulin in atypical ductal hyperplasia and carcinoma of the breast. Cancer Sci 100(4):580-587

50. Mao XY, Fan CF, Zheng HC, Wei J, Yao F, Jin F (2010) p53 nuclear accumulation and ERalpha expression in ductal hyperplasia of breast in a cohort of 215 Chinese women. J Exp Clin Cancer Res 29(1):112

51. Barnes R, Masood S (1990) Potential value of hormone receptor assay in carcinoma in situ of breast. Am J Clin Pathol 94(5):533-537

52. Ding L, Erdmann C, Chinnaiyan AM, Merajver SD, Kleer CG (2006) Identification of EZH2 as a molecular marker for a precancerous state in morphologically normal breast tissues. Cancer Res 66(8):4095-4099

53. Shi B, Liang J, Yang X, Wang Y, Zhao Y, Wu H, Sun L, Zhang Y, Chen Y, Li R, Zhang Y, Hong M, Shang Y (2007) Integration of estrogen and Wnt signaling circuits by the polycomb group protein EZH2 in breast cancer cells. Mol Cell Biol 27(14):5105-5119

54. Roger P, Sahla ME, Makela S, Gustafsson JA, Baldet P, Rochefort H (2001) Decreased expression of estrogen receptor beta protein in proliferative preinvasive mammary tumors. Cancer Res 61(6):2537-2541
55. Chantzi NI, Palaiologou M, Stylianidou A, Goutas N, Vassilaros S, Kourea HP, Dhimolea E, Mitsiou DJ, Tiniakos DG, Alexis MN (2014) Estrogen receptor beta2 is inversely correlated with $\mathrm{Ki}-67$ in hyperplastic and noninvasive neoplastic breast lesions. J Cancer Res Clin Oncol 140(6):1057-1066

56. Gao X, Fisher SG, Emami B (2003) Risk of second primary cancer in the contralateral breast in women treated for earlystage breast cancer: a population-based study. Int J Radiat Oncol Biol Phys 56(4):1038-1045

57. Robbins GF, Berg JW (1964) Bilateral primary breast cancer: a prospective clincopathological study. Cancer 17:1501-1527

58. Samant RS, Olivotto IA, Jackson JS, Mates D (2001) Diagnosis of metachronous contralateral breast cancer. Breast $\mathbf{J}$ 7(6):405-410

59. Dowsett M, Cuzick J, Ingle J, Coates A, Forbes J, Bliss J, Buyse M, Baum M, Buzdar A, Colleoni M, Coombes C, Snowdon C, Gnant M, Jakesz R, Kaufmann M, Boccardo F, Godwin J, Davies C, Peto R (2010) Meta-analysis of breast cancer outcomes in adjuvant trials of aromatase inhibitors versus tamoxifen. J Clin Oncol 28(3):509-518. doi:10.1200/jco.2009.23.1274

60. Adrales G, Turk P, Wallace T, Bird R, Norton HJ, Greene F (2000) Is surgical excision necessary for atypical ductal hyperplasia of the breast diagnosed by Mammotome? Am J Surg 180(4):313-315

61. Cohen MA (2004) Cancer upgrades at excisional biopsy after diagnosis of atypical lobular hyperplasia or lobular carcinoma in situ at core-needle biopsy: some reasons why. Radiology 231(3):617-621. doi:10.1148/radiol.2313040154

62. Jackman RJ, Birdwell RL, Ikeda DM (2002) Atypical ductal hyperplasia: can some lesions be defined as probably benign after stereotactic 11-gauge vacuum-assisted biopsy, eliminating the recommendation for surgical excision? Radiology 224(2):548-554. doi:10.1148/radiol.2242011528

63. Lourenco AP, Mainiero MB, Lazarus E, Giri D, Schepps B (2007) Stereotactic breast biopsy: comparison of histologic underestimation rates with 11- and 9-gauge vacuum-assisted breast biopsy. Am J Roentgenol 189(5):W275-W279. doi:10. 2214/ajr.07.2165

64. Margenthaler JA, Duke D, Monsees BS, Barton PT, Clark C, Dietz JR (2006) Correlation between core biopsy and excisional biopsy in breast high-risk lesions. Am J Surg 192(4):534-537. doi:10.1016/j.amjsurg.2006.06.003

65. Brem RF, Lechner MC, Jackman RJ, Rapelyea JA, Evans WP, Philpotts LE, Hargreaves J, Wasden S (2008) Lobular neoplasia at percutaneous breast biopsy: variables associated with carcinoma at surgical excision. Am J Roentgenol 190(3):637-641. doi:10.2214/ajr.07.2768

66. Eby PR, Ochsner JE, DeMartini WB, Allison KH, Peacock S, Lehman CD (2009) Frequency and upgrade rates of atypical ductal hyperplasia diagnosed at stereotactic vacuum-assisted breast biopsy: 9-versus 11-gauge. Am J Roentgenol 192(1):229-234. doi:10.2214/ajr.08.1342

67. Kohr JR, Eby PR, Allison KH, DeMartini WB, Gutierrez RL, Peacock S, Lehman CD (2010) Risk of upgrade of atypical ductal hyperplasia after stereotactic breast biopsy: effects of number of foci and complete removal of calcifications. Radiology 255(3):723-730. doi:10.1148/radiol.09091406

68. Winchester DJ, Bernstein JR, Jeske JM, Nicholson MH, Hahn EA, Goldschmidt RA, Watkin WG, Sener SF, Bilimoria MB, Barrera E, Jr, Winchester DP (2003) Upstaging of atypical ductal hyperplasia after vacuum-assisted 11-gauge stereotactic core needle biopsy. Arch Surg 138(6):619-622. doi:10.1001/ archsurg.138.6.619

69. Ibrahim N, Bessissow A, Lalonde L, Mesurolle B, Trop I, Lisbona A, El-Khoury M (2012) Surgical outcome of biopsy-proven lobular neoplasia: is there any difference between lobular 
carcinoma in situ and atypical lobular hyperplasia? Am J Roentgenol 198(2):288-291. doi:10.2214/ajr.11.7212

70. Tavassoli FA, Norris HJ (1990) A comparison of the results of long-term follow-up for atypical intraductal hyperplasia and intraductal hyperplasia of the breast. Cancer 65(3):518-529

71. Marinho AF, Botelho M, Schmitt FC (2000) Evaluation of numerical abnormalities of chromosomes 1 and 17 in proliferative epithelial breast lesions using fluorescence in situ hybridization. Pathol Res Pract 196(4):227-233

72. Krishnamurthy S, Zhao L, Hayes K, Glassman AB, Cristofanilli M, Singletary SE, Hunt KK, Kuerer HM, Sneige N (2004) Feasibility and utility of using chromosomal aneusomy to further define the cytologic categories in nipple aspirate fluid specimens: a preliminary study. Cancer 102(5):322-327

73. Visscher DW, Wallis TL, Crissman JD (1996) Evaluation of chromosome aneuploidy in tissue sections of preinvasive breast carcinomas using interphase cytogenetics. Cancer 77(2):315320

74. King EB, Chew KL, Hom JD, Duarte LA, Mayall B, Miller TR, Neuhaus JM, Wrensch MR, Petrakis NL (1991) Characterization by image cytometry of duct epithelial proliferative disease of the breast. Mod Pathol 4(3):291-296

75. Schimmelpenning H, Eriksson ET, Falkmer UG, Azavedo E, Svane G, Auer GU (1992) Expression of the c-erbB-2 protooncogene product and nuclear DNA content in benign and malignant human breast parenchyma. Virchows Arch A 420(5):433-440

76. Eriksson ET, Schimmelpenning H, Aspenblad U, Zetterberg A, Auer GU (1994) Immunohistochemical expression of the mutant p53 protein and nuclear DNA content during the transition from benign to malignant breast disease. Hum Pathol 25(11):12281233

77. Carpenter R, Gibbs N, Matthews J, Cooke T (1987) Importance of cellular DNA content in pre-malignant breast disease and preinvasive carcinoma of the female breast. Br J Surg 74(10):905906

78. Schmitt FC, Figueiredo P, Lacerda M (1995) Expression of c-erb B-2 protein and DNA ploidy in breast carcinogenesis. Arch Pathol Lab Med 119(9):815-820

79. Fabian CJ, Kimler BF, Zalles CM, Klemp JR, Kamel S, Zeiger S, Mayo MS (2000) Short-term breast cancer prediction by random periareolar fine-needle aspiration cytology and the Gail risk model. J Natl Cancer Inst 92(15):1217-1227

80. Teplitz RL, Butler BB, Tesluk H, Min BH, Russell LA, Jensen HM, Hill LR (1990) Quantitative DNA patterns in human preneoplastic breast lesions. Anal Quant Cytol Histol 12(2):98-102

81. De Potter CR, Praet MM, Slavin RE, Verbeeck P, Roels HJ (1987) Feulgen DNA content and mitotic activity in proliferative breast disease. A comparison with ductal carcinoma in situ. Histopathology 11(12):1307-1319

82. Dietrich CU, Pandis N, Teixeira MR, Bardi G, Gerdes AM, Andersen JA, Heim S (1995) Chromosome abnormalities in benign hyperproliferative disorders of epithelial and stromal breast tissue. Int J Cancer 60(1):49-53

83. Aubele MM, Cummings MC, Mattis AE, Zitzelsberger HF, Walch AK, Kremer M, Hofler H, Werner M (2000) Accumulation of chromosomal imbalances from intraductal proliferative lesions to adjacent in situ and invasive ductal breast cancer. Diagn Mol Pathol 9(1):14-19

84. Mastracci TL, Shadeo A, Colby SM, Tuck AB, O'Malley FP, Bull SB, Lam WL, Andrulis IL (2006) Genomic alterations in lobular neoplasia: a microarray comparative genomic hybridization signature for early neoplastic proliferationin the breast. Genes Chromosomes Cancer 45(11):1007-1017

85. O'Connell P, Pekkel V, Fuqua SA, Osborne CK, Clark GM, Allred DC (1998) Analysis of loss of heterozygosity in 399 premalignant breast lesions at 15 genetic loci. J Natl Cancer Inst 90(9):697-703

86. Lu YJ, Osin P, Lakhani SR, Di Palma S, Gusterson BA, Shipley JM (1998) Comparative genomic hybridization analysis of lobular carcinoma in situ and atypical lobular hyperplasia and potential roles for gains and losses of genetic material in breast neoplasia. Cancer Res 58(20):4721-4727

87. Tibiletti MG, Sessa F, Bernasconi B, Cerutti R, Broggi B, Furlan D, Acquati F, Bianchi M, Russo A, Capella C, Taramelli R (2000) A large 6q deletion is a common cytogenetic alteration in fibroadenomas, pre-malignant lesions, and carcinomas of the breast. Clin Cancer Res 6(4):1422-1431

88. Tidow N, Boecker A, Schmidt H, Agelopoulos K, Boecker W, Buerger H, Brandt B (2003) Distinct amplification of an untranslated regulatory sequence in the egfr gene contributes to early steps in breast cancer development. Cancer Res 63(6): 1172-1178

89. Ellsworth RE, Ellsworth DL, Deyarmin B, Hoffman LR, Love B, Hooke JA, Shriver CD (2005) Timing of critical genetic changes in human breast disease. Ann Surg Oncol 12(12):1054-1060

90. Chuaqui RF, Zhuang Z, Emmert-Buck MR, Liotta LA, Merino MJ (1997) Analysis of loss of heterozygosity on chromosome $11 \mathrm{q} 13$ in atypical ductal hyperplasia and in situ carcinoma of the breast. Am J Pathol 150(1):297-303

91. Nayar R, Zhuang Z, Merino MJ, Silverberg SG (1997) Loss of heterozygosity on chromosome 11q13 in lobular lesions of the breast using tissue microdissection and polymerase chain reaction. Hum Pathol 28(3):277-282

92. Tsuda H, Takarabe T, Akashi-Tanaka S, Fukutomi T, Hirohashi S (2001) Pattern of chromosome 16q loss differs between an atypical proliferative lesion and an intraductal or invasive ductal carcinoma occurring subsequently in the same area of the breast. Mod Pathol 14(5):382-388

93. Mastracci TL, Tjan S, Bane AL, O’Malley FP, Andrulis IL (2005) E-cadherin alterations in atypical lobular hyperplasia and lobular carcinoma in situ of the breast. Mod Pathol 18(6):741-751

94. Lakhani SR, Collins N, Stratton MR, Sloane JP (1995) Atypical ductal hyperplasia of the breast: clonal proliferation with loss of heterozygosity on chromosomes $16 \mathrm{q}$ and $17 \mathrm{p}$. J Clin Pathol 48(7):611-615

95. Kaneko M, Arihiro K, Takeshima Y, Fujii S, Inai K (2002) Loss of heterozygosity and microsatellite instability in epithelial hyperplasia of the breast. J Exp Ther Oncol 2(1):9-18

96. Werner M, Mattis A, Aubele M, Cummings M, Zitzelsberger H, Hutzler P, Hofler H (1999) 20q13.2 amplification in intraductal hyperplasia adjacent to in situ and invasive ductal carcinoma of the breast. Virchows Arch 435(5):469-472

97. Bean GR, Ibarra DC, Goldenberg VK, Baker JC Jr, Troch MM, Paisie C, Wilke LG, Yee L, Marcom PK, Kimler BF, Fabian CJ, Zalles CM, Broadwater G, Scott V, Seewaldt VL (2007) Hypermethylation of the breast cancer-associated gene 1 promoter does not predict cytologic atypia or correlate with surrogate end points of breast cancer risk. Cancer Epidemiol Biomarkers Prev 16(1):50-56

98. Evron E, Dooley WC, Umbricht CB, Rosenthal D, Sacchi N, Gabrielson E, Soito AB, Hung DT, Ljung B, Davidson NE, Sukumar S (2001) Detection of breast cancer cells in ductal lavage fluid by methylation-specific PCR. Lancet 357(9265):1335-1336

99. Umbricht CB, Evron E, Gabrielson E, Ferguson A, Marks J, Sukumar S (2001) Hypermethylation of 14-3-3 sigma (stratifin) is an early event in breast cancer. Oncogene 20(26):3348-3353

100. van Hoesel AQ, Sato Y, Elashoff DA, Turner RR, Giuliano AE, Shamonki JM, Kuppen PJ, van de Velde CJ, Hoon DS (2013) 
Assessment of DNA methylation status in early stages of breast cancer development. Br J Cancer 108(10):2033-2038

101. Liu T, Niu Y, Yu Y, Liu Y, Zhang F (2009) Increased gammatubulin expression and P16INK4A promoter methylation occur together in preinvasive lesions and carcinomas of the breast. Ann Oncol 20(3):441-448

102. Liu T, Niu Y, Feng Y, Niu R, Yu Y, Lv A, Yang Y (2008) Methylation of $\mathrm{CpG}$ islands of p16(INK4a) and cyclinD1 overexpression associated with progression of intraductal proliferative lesions of the breast. Hum Pathol 39:1637-1646

103. Visscher DW, Pankratz VS, Santisteban M, Reynolds C, Ristimaki A, Vierkant RA, Lingle WL, Frost MH, Hartmann LC (2008) Association between cyclooxygenase-2 expression in atypical hyperplasia and risk of breast cancer. J Natl Cancer Inst 100(6):421-427. doi:10.1093/jnci/djn036

104. Weinstat-Saslow D, Merino MJ, Manrow RE, Lawrence JA, Bluth RF, Wittenbel KD, Simpson JF, Page DL, Steeg PS (1995) Overexpression of cyclin D mRNA distinguishes invasive and in situ breast carcinomas from non-malignant lesions. Nat Med 1(12): $1257-1260$

105. Alle KM, Henshall SM, Field AS, Sutherland RL (1998) Cyclin D1 protein is overexpressed in hyperplasia and intraductal carcinoma of the breast. Clin Cancer Res 4(4):847-854

106. Zhu XL, Hartwick W, Rohan T, Kandel R (1998) Cyclin D1 gene amplification and protein expression in benign breast disease and breast carcinoma. Mod Pathol 11(11):1082-1088

107. Gatalica Z, Lele SM, Rampy BA, Norris BA (2000) The expression of Fhit protein is related inversely to disease progression in patients with breast carcinoma. Cancer 88(6):13781383

108. Wang TT, Frezza EE, Ma R, Hu SY, Liu CZ, Zhang GY, Wachtel MS, Lu XM, Feng JB, Lu CX (2008) Loss expression of active fragile sites genes associated with the severity of breast epithelial abnormalities. Chin Med J 121(20):1969-1974

109. Xu R, Perle MA, Inghirami G, Chan W, Delgado Y, Feiner H (2002) Amplification of Her-2/neu gene in Her-2/neu-overexpressing and -nonexpressing breast carcinomas and their synchronous benign, premalignant, and metastatic lesions detected by FISH in archival material. Mod Pathol 15(2):116-124

110. Eren F, Calay Z, Durak H, Eren B, Comunoglu N, Aydin O (2012) C-Erb-b2 oncogene expression in intraductal proliferative lesions of the breast. Bosnian J Basic Med Sci 12(1):41-50

111. Mazzini RC, Elias S, Nazario AC, Kemp C, Logullo AF (2009) Prevalence of c-myc expression in breast lesions associated with microcalcifications detected by routine mammography. Sao Paulo Med J 127(2):66-70

112. Gillett CE, Lee AH, Millis RR, Barnes DM (1998) Cyclin D1 and associated proteins in mammary ductal carcinoma in situ and atypical ductal hyperplasia. J Pathol 184(4):396-400

113. Shi A, Dong J, Hilsenbeck S, Bi L, Zhang H, Li Y (2015) The status of STAT3 and STAT5 in human breast atypical ductal hyperplasia. PLoS ONE 10(7):e0132214

114. Chin K, de Solorzano CO, Knowles D, Jones A, Chou W, Rodriguez EG, Kuo WL, Ljung BM, Chew K, Myambo K, Miranda M, Krig S, Garbe J, Stampfer M, Yaswen P, Gray JW, Lockett SJ (2004) In situ analyses of genome instability in breast cancer. Nat Genet 36(9):984-988

115. Yashima K, Milchgrub S, Gollahon LS, Maitra A, Saboorian MH, Shay JW, Gazdar AF (1998) Telomerase enzyme activity and RNA expression during the multistage pathogenesis of breast carcinoma. Clin Cancer Res 4(1):229-234

116. Song M, Mi X, Li B, Zhu J, Gao Y, Cui S, Song J (2002) Expression of telomerase genes in cancer development in atypical hyperplasia of the mammary duct. Chin Med J 115(8):1221-1225

117. Guan H, Sun Y, Zan Q, Xu M, Li Y, Zhou J, He E, Eriksson S, Wen W, Skog S (2009) Thymidine kinase 1 expression in atypical ductal hyperplasia significantly differs from usual ductal hyperplasia and ductal carcinoma in situ: a useful tool in tumor therapy management. Mol Med Rep 2(6):923-929

118. Rosenberg CL, Larson PS, Romo JD, de las MA, Faller DV (1997) Microsatellite alterations indicating monoclonality in atypical hyperplasias associated with breast cancer. Hum Pathol 28(2):214-219 